\title{
Spelling in the context of writing:
}

\author{
An investigation \\ of the knowledge and strategies used \\ by average and below average writers \\ after three years at school
}

Helen Pentecost

A three paper thesis submitted in partial fulfilment of the degree

of Master of Education

Victoria University of Wellington

2010 


\section{Abstract}

After three years of schooling, some primary students are behind the expected levels for spelling achievement. This qualitative case study sought an insider view from 12 Year 4 students on the strategies they used to spell words within the context of classroom writing programmes. The students in the study attended three primary schools. Half the students had been identified by their teachers as achieving below the expected level in spelling for their year group and half at the expected level. Data were collected through a series of semi-structured interviews with groups of students and individual interviews with teachers from their schools. Data were also gathered from analysis of the students' writing samples. A comparison was made between the data gathered from the two groups of students, searching for similarities and differences in their strategies and understandings about spelling. Data from the students were also compared to the teachers' views about how students learn to spell. The average-achieving students viewed new words as problems that can be solved through using a combined repertoire of strategies. These included drawing on visual memory, using phoneme-grapheme relationships and morphological strategies to spell challenging words. In contrast, the below average achievers had a more limited range of strategies, tending to use only one strategy at a time and did not readily making links to their prior knowledge. If teachers are aware of these strategies and how successful spellers combine appropriate strategies, they can assist students to improve their spelling by giving specific instruction and feedback on their use. 


\section{Acknowledgements}

In undertaking this study there are many people who have provided support and encouragement throughout my journey. I wish to acknowledge my appreciation and thanks for all they have done.

Firstly, I thank my supervisor Dr John Dickie who has assisted me greatly through the process. Thank you for always being available and helping me to clarify the vision and to think in new dimensions. My learning has been immense over the time that I have worked with you.

To the three principals who allowed me into your schools and made me feel so welcome, thank you very much. Without your agreement there would have been no study.

To all the teachers who took part, thank you for giving me your time and freely offering your thoughts and ideas. It was great working along side such a professional group of teachers.

To the students and their parents, thank you for agreeing to participate. To the students thank you for freely giving your ideas. You are a very inspiring group of students who all have interesting perspectives, which I could not have done without.

To my school principal, thank you for supporting my study, being a good listener and for assistance in many ways.

To my work colleagues, your continued interest and support has been always appreciated.

Finally I would like to thank all my family for their continual interest and support. I particularly thank my husband and two daughters for their support and encouragement. 


\section{Table of Contents}

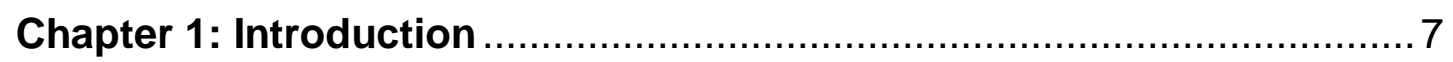

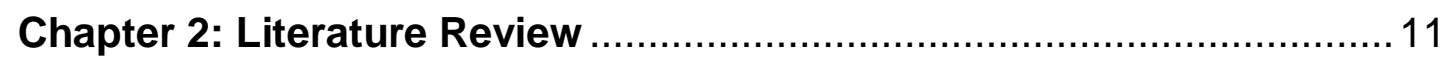

Curriculum guidelines for teachers ................................................. 12

Why spelling is important ............................................................ 13

High frequency words ................................................................ 14

Expectations for Year 4 students ..................................................... 15

Learning the code is a developmental process....................................... 15

Strategies for spelling ................................................................. 17

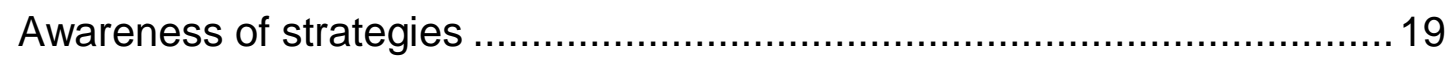

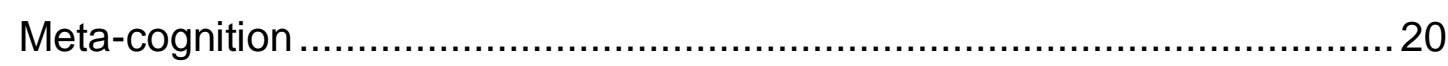

Daily writing and use of teacher feedback ......................................... 21

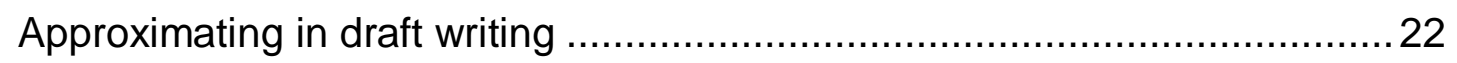

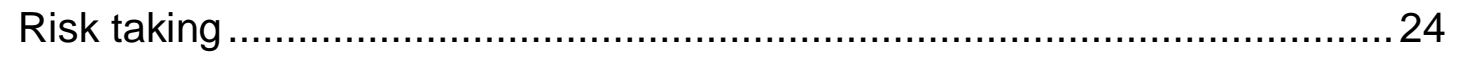

Instructional Match and the Zone of Proximal Development......................24

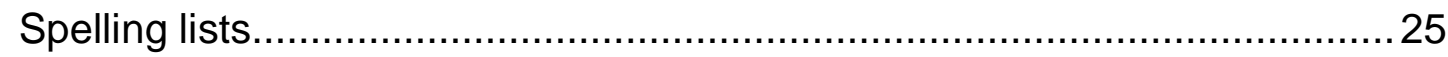

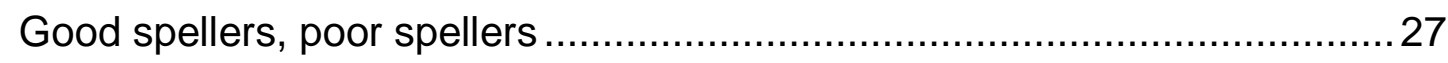

Use of computers for writing and spelling .......................................... 28

Summary of literature ................................................................... 29

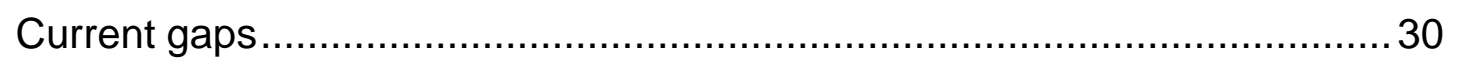

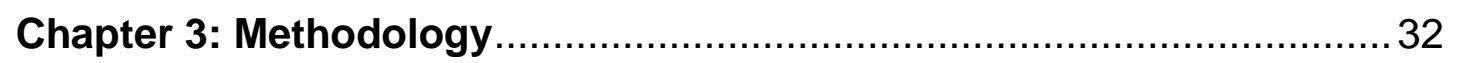

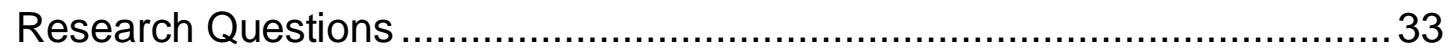

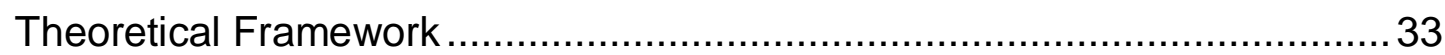

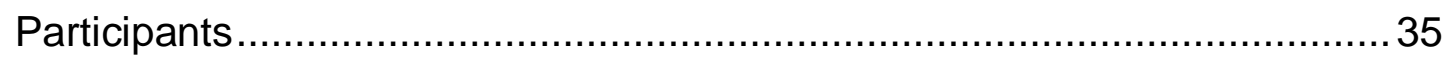

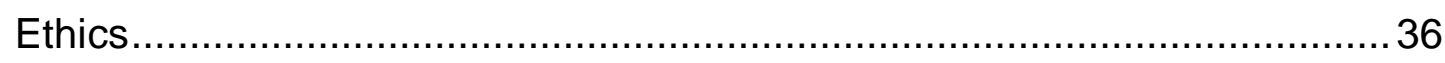

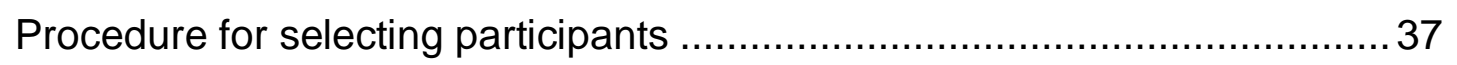

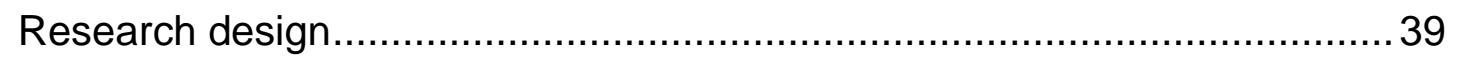

Profile of the participating students .................................................. 43 
Chapter 4: Results and Discussion - The students' views .................... 45

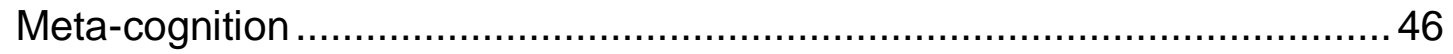

Strategies used to spell words ...................................................... 47

Strategies used by Year 4 students who are achieving below expected

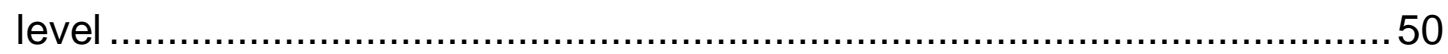

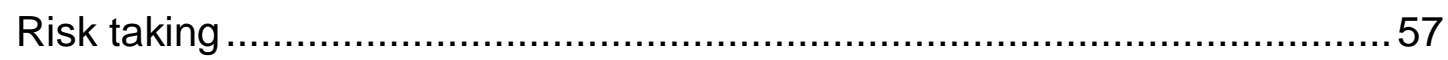

Impact of class spelling programmes on spelling knowledge ....................57

Use of class peers to assist with spelling.............................................. 59

Use of computers to assist with spelling ............................................6 60

Beliefs on the importance of correct spelling ......................................61

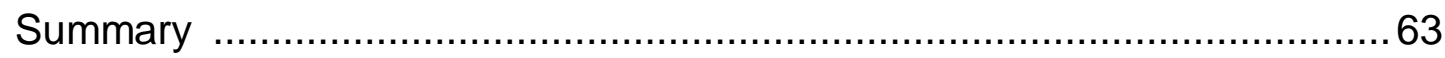

Strategies used by Year 4 students who are achieving at expected level ....65

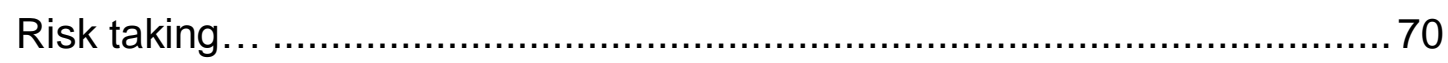

Impact of class spelling programmes on spelling knowledge ....................71

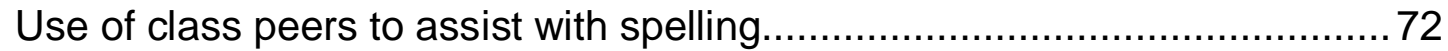

Use of computers to assist with spelling .............................................. 73

Beliefs on the importance of correct spelling ..................................... 75

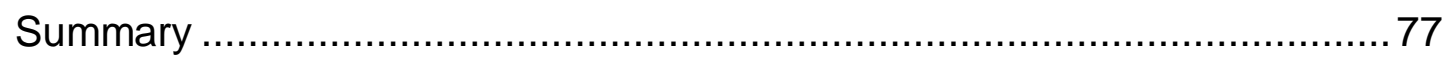

Summary and comparison of the two groups ..................................... 78

Chapter 5: Results and Discussion - The teachers' views ................. 81

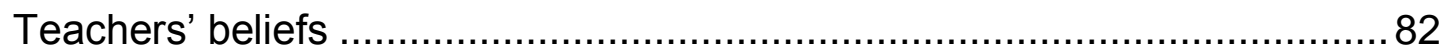

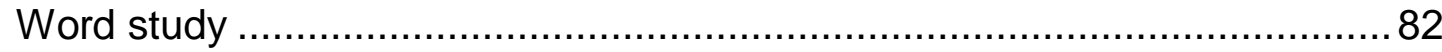

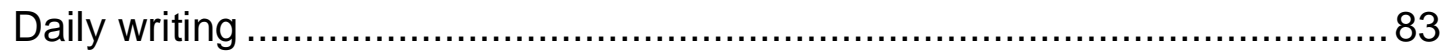

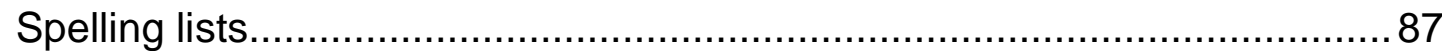

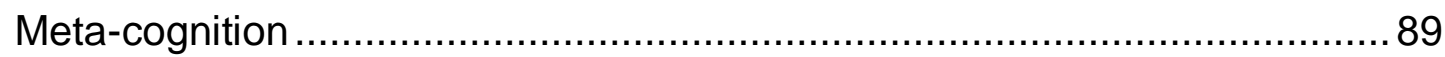

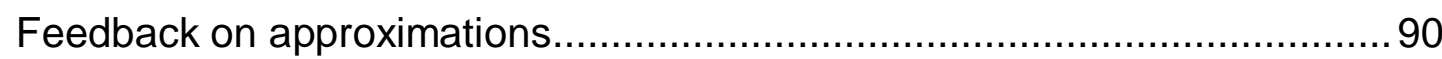

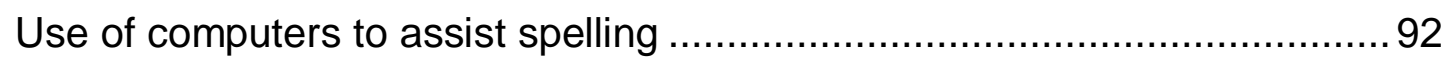

Conclusions from teachers' and students' views .................................... 94

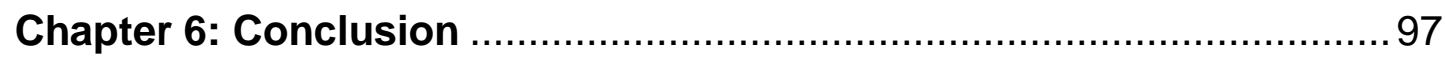

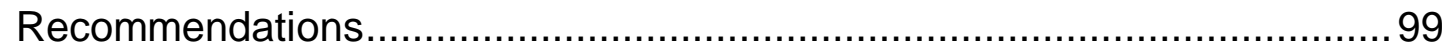

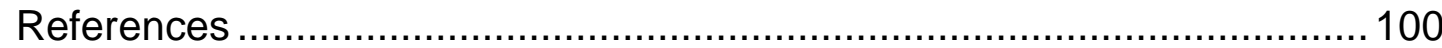

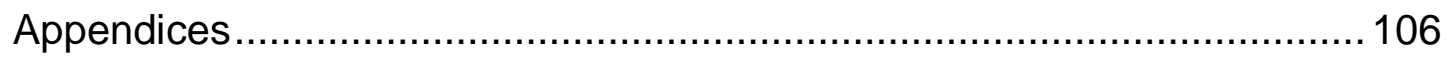




\section{Appendices}

Appendix A: Letter of explanation for principals .................................. 106

Appendix B: Consent form for principals........................................ 109

Appendix C: Letter of explanation for teachers ................................. 111

Appendix D: Consent form for teachers....................................... 113

Appendix E: Letter of explanation for parents and caregivers ..................115

Appendix F: Consent form for parents and caregivers........................ 117

Appendix G: Letter of explanation for students ................................. 119

Appendix H: Consent form for students ..................................... 121

Appendix I: Interview Schedule 1 for students .................................. 123

Appendix J: Interview schedule 2 for students.................................... 124

Appendix K: Interview Schedule 3 for students ................................ 127

Appendix L: Interview Schedule 1 for teachers................................ 130

Appendix M: Interview Schedule 2 for teachers ............................... 131

Appendix N: asTTle Writing Test ............................................... 133

Appendix O: Essential Words for Spelling and Writing .......................... 135 


\section{CHAPTER 1}

\section{Introduction}

Spelling is, for many people, a measure of writing competency. Widely held views consider correct spelling is important for two main reasons. Firstly ease of spelling frees up the writer's resources to enable focus on deeper features (Graham \& Harris, 2006), which includes communicating information clearly and expressing ideas. When words do not flow automatically, the content of the writing suffers as the student's attention is switched from composing to the spelling (Hood, 2000; Graham et al., 2006; Graves, 2003).

The second important reason is that correct spelling assists with the clarity of meaning. When the spelling is poor, errors can distract the reader. Therefore, correct spelling, with its accepted conventions, enables the audience to more easily interpret the message (Graves, 2003; Hood, 2000; Phenix \& Scott-Dunne, 1991).

\section{Significance}

There have been concerns about the standards of literacy achievement of students in New Zealand schools for many years. A taskforce was set up in the 1990s with a resulting report: The Report of the Literacy Taskforce (Ministry of Education, 1999). Following recommendations in the report, many new resources were produced for teachers including Effective Literacy Practice in Years 1 to 4 (Ministry of Education, 2003). This resource provides much useful direction for the teaching of English including the teaching of spelling.

The thrust of literacy development also resulted in many schools joining with neighbouring groups of schools in the Ministry of Education initiated Cluster Schools' Improvement Projects (Ministry of Education, 2010c). The Cluster Schools' 
Improvement Projects (Ministry of Education, 2010c) took shape after nationwide concerns about the level of qualifications students have achieved on leaving secondary school, with many students leaving with no qualifications. When a student falls below the expected level in any year in primary school, it is very hard to catch up to the level for expected their age group, and the gap between them and their peers is likely to widen increasingly.

Recent documents have made more specific links between expected achievement and years at school. The New Zealand Curriculum Reading and Writing Standards for years 1-8 (Ministry of Education, 2009c) clearly sets out expected skills at each year level at primary school. The Standards link to The Literary Learning Progressions (Ministry of Education, 2010a). For spelling, the progressions state that after three years at school, students should be proof-reading their writing through recognition of spelling errors and applying fix-up strategies.

Most New Zealand children enter school on or around their fifth birthday. After approximately three years of primary schooling, a student enters Year 4. Indicators outlined in The New Zealand Curriculum (Ministry of Education, 2007) show that by Year 4, achievement should be within Level 2 on the curriculum framework. Accordingly, Year 4 students who are working in literacy within Level one in the New Zealand Curriculum, are well below expected level and "at risk" of not catching up, and ever reaching expected standard for their year level. If these students do not quickly progress to working within the Level 2 range, it will be increasingly difficult for them to achieve at the expected level of success. Therefore, it is timely in Year 4, to examine the strategies successful students use as they gain independence in their learning, and how these strategies differ for the less successful students. Barriers to achievement for those students falling below expectations in Year 4 are worthy of 
investigation. The National Education Goals (Ministry of Education, 2009a) state that removing barriers to achievement and an emphasis on literacy are priorities. Therefore a study that includes Year 4 students who are not achieving at expected levels in spelling, may be beneficial to identify any gaps in knowledge or barriers to achievement. It is significant, as issues that restrict or enhance learners' success may be identified.

As a Resource Teacher Learning and Behaviour (RTLB), I have been involved in working with teachers who are seeking answers to why a group of students are struggling with literacy, including the spelling component of writing. The cluster of primary schools I work in, and the secondary school these primary schools contribute to, have identified low literacy achievement as an issue to be addressed. As a result of this identification, the schools are working collectively on a Ministry of Education initiated Cluster Schools Improvement Project (Ministry of Education, 2010c). The schools are combining efforts to improve literacy achievement towards raising the secondary school's New Zealand Certificate in Educational Achievement (NCEA).

In line with the aim of improving literacy levels, this research seeks to identify direction for teaching students that are achieving below Level 2 (Ministry of Education, 2007) in the spelling component of writing. Analysis of information on the spelling strategies used by a group of Year 4 students, will contribute to the literacy professional development that schools have access to, and may assist in closing the gaps for at risk students before it is too late. This may in turn contribute to removing barriers to achievement, through closer identification of needs for low achievers.

When considering how and why some students have literacy difficulties, it is useful to find out about the strategies used by students who are not having difficulty (Brann, 2004; Snowling \& Stackhouse (1996). Through comparing information gained 
from successful achievers, with information from lower achievers, some answers about the differences in strategy use may emerge. Through interviewing the students, an insider perspective is gained from the students' own voices.

The New Zealand Exemplars (Ministry of Education, 2010d), and asTTle (Ministry of Education, 2010e) describe spelling as a surface feature of writing alongside punctuation, grammar and layout. Surface features are the tools to enable the message to be written, and are not the actual message. As Hood (2000) points out, "Spelling is a tool of written expression and not an end in itself" (p. 72). Its importance lies in its use within the context of continuous writing. Therefore, this study seeks to examine the strategies students use to spell words in the context of their own writing.

Chapter 1 has introduced us to the importance of spelling and why an investigation can contribute to our understanding of those students who are having difficulty with spelling. Chapter 2 reviews the literature that considers why spelling is important and the processes that are involved in becoming a successful speller in writing. 


\section{CHAPTER 2}

\section{Literature Review}

The previous chapter introduced us to the significance of a study of spelling, in the context of community and nation-wide concerns about the standard of literacy levels. This chapter outlines why proficient spelling is important and it discusses the processes that are involved in gaining proficiency in spelling.

The English writing system is alphabetic, with letter symbols being used in combinations to record words. This not the case in all languages, Some languages are written in the form of signs to represent entire words. English has 26 letters, which are used to represent approximately 44 individual sounds or phonemes (Emmitt, Pollock and Limbrick, 1996; Smith and Elley, 1997).

The English language has been influenced by many historical events with French, Latin and Greek languages being major influences. Before 1500AD English words were spelt as they sounded, with dialect affecting pronunciation and consequently the spelling being inconsistent. Then the writing of dictionaries lead to more consistency in spelling, with Dr Samuel Johnson's dictionary in 1755 (Emmitt et al., 1996), having a marked effect on standardising English spelling. With the standardising the spelling of words, the diverse dialects within the English language do not influence current spellings to the degree that they did before dictionaries.

\section{Why study English}

Literacy in English provides for participation in life in New Zealand and the world, socially, culturally and economically. Written communication is an important part of English learning (Ministry of Education, 2007). Information and communication technologies are also important for communication of language, and participation in the wider community (Ministry of Education, 1994). Becoming literate is a complex 
process for students to learn. Guidelines for teachers, have for some time, attempted to address the complexities involved in literacy teaching.

\section{Curriculum guidelines for teachers}

Following concerns about literacy levels of New Zealand students in the 1990s, the Government set up a task force to investigate literacy achievement in New Zealand. The resulting report, The Report of the Literacy Taskforce (Ministry of Education, 1999) had a number of recommendations. At the forefront of the recommendations was the stated goal that "by 2005, every child turning nine will be able to read, write and do maths for success" (Ministry of Education, 1999, p. 4). The Taskforce recommended greater assistance for teachers on appropriate approaches. However, the taskforce was not recommending a step-by-step teaching formula. It pointed to the need for more resources to be available to enable teachers to select appropriate instructional approaches, particularly for under-achieving students.

As a result of these recommendations in the Taskforce, a new teachers' resource, Effective Literacy Practice in Years 1 to 4 (Ministry of Education, 2003) was produced. This resource provides much useful direction for the teaching of English. Three core curriculum documents followed to assist teachers with planning for their students' literacy needs. First was the over-arching document, The New Zealand Curriculum for English-medium teaching and learning in years 1-13 (Ministry of Education, 2007).

The next two documents have been more assertive in the messages about standards of achievement than past direction has been. The Literary Learning Progressions (Ministry of Education, 2010a) and The New Zealand Curriculum Reading and Writing Standards (Ministry of Education, 2009c) have stated expectations in literacy achievement for the end of each of the child's school years up 
to the end of Year 3. After Year 3, the measurements are placed in school years rather than referring to individual student's years at school. Clear guidelines are given for expected achievement of each year level in Reading and Writing. While acknowledging that the acquisition of literacy is a complex process, and there are many components that contribute to students' success, this study's particular focus is on the spelling component of writing.

\section{Why spelling is important}

When writing to communicate, we need to be competent with the tools of the trade. One of these important tools is the knowledge of how to spell the words needed for written communication. "Spelling contributes to this communication, but it is not the purpose of the communication (Croft, 2004).

Spelling is, for many people, a measure of writing competency. Society expects that schools will produce students who can spell most words (Smith et al., 1997). Spelling accuracy is viewed by many people as an important measure of a student's literacy progress. However, we need to view spelling use as a tool within the context of writing. As Hood (2000) points out, "Spelling is a tool of written expression and not an end in itself' (p. 72). Therefore when considering the importance of spelling correctness and how we teach it, we need to consider its use in the context of continuous writing. The Ministry of Education (2003) guides us by stating, "Writers need to develop the ability to use conventional spelling so that their writing is clear, fluent and accurate".

Widely held views consider correct spelling is important for two main reasons (Graves, 2003; Hood, 2000). Firstly, when a student has developed fluency in spelling, and the message is written with speed and ease, the student's focus can be more on communicating information clearly and expressing ideas. When words do not 
flow automatically, the content of the writing suffers as the student's attention is switched from composing to the spelling (Graham et al., 2006; Graves, 2003; Hood, 2000). When processing of information (such as spelling) is fluent and requires little effort or attention, it is known as automaticity (Davis, 2007).

The second important reason is that correct spelling assists with the clarity of meaning. When the spelling is poor, errors can distract the reader. Therefore, correct spelling, with its accepted conventions, enables the audience to more easily interpret the message (Graves, 2003; Hood, 2000; Phenix et al., 1991).

As discussed in Chapter One, The students in this study have attended a New Zealand primary school for at least three years and are attending Year 4 classes. The guidelines for teaching spelling in The Literacy Learning Progressions (Ministry of Education, 2010a) state that students who have attended school for three years, will proof-read their writing to check spelling, using classroom resources such as junior dictionaries. They will draw on skills that include encoding unfamiliar words through the use of phoneme-grapheme relationships and awareness of spelling patterns, along with applying knowledge of rules. The guidelines state that students will also use their visual memory to spell personal and high-frequency words.

\section{High frequency words}

The words that are most frequently used by writers are often referred to as high frequency words. The high freqency words are listed in the Spell-Write resource (Croft and Mapa, 1998). This resource is used in many New Zealand classrooms. It contains words listed in alphabetical order. A feature of the resource is the section of the "Essential Words" (Croft et al., 1998, pp. 32-34; See Appendix O). These highfrequency words are grouped in lists, one through to seven, according to their frequency of use. List 1 contains the 10 most often used words in written English. 


\section{Expectations for Year 4 students}

There is an expectation by the Ministry of Education that students will spell personal and high-frequency words using their visual memory. The Literacy Learning Progressions (Ministry of Education, 2010a) states an expectation that after three years at school, students will be able to to spell many words from the essential lists 1 4 and some words from list 5 and list 6 of the essential words in the Spell-Write resource.

The New Zealand Curriculum Reading and Writing Standards (Ministry of Education, 2009c) states that at the end of a student's third year, they will be working towards Level 2 in writing (of which spelling is a component), and at the end of Year 4 they will be meeting the demands of Level 2. However, The New Zealand Curriculum (Ministry of Education, 2007) discusses curriculum levels in relation to school years. It would be expected that a student would be working within Level 2 in English when they have attended school for three years and are in Year 4 at school. Therefore, if a student is working at Level 1 at the beginning of Year 4, according to The New Zealand Curriculum (Ministry of Education, 2007), he/she would be working below the expected level.

\section{Learning the code is a developmental process}

Spelling begins with the spoken word and the need for the sounds to be written down (Brann, 2004). English spelling has many historical influences in its orthography and morphology. Although there can be difficulties in making the right choices when spelling a word, there are also many regularities and consistencies between sounds and letters (Allcock, 2006). Allcock is keen to point out that letters do not make sounds but represent the sounds. The Ministry of Education acknowledges this, stating, "Spelling is naming or writing accurately, and in the right order, the letters that 
represent sounds or sound patterns in words" (Ministry of Education, 2010b). However this definition could over-simplify the complexity of learning to spell, especially without a specific reference to morphological influences.

As with other learning, such as speaking or walking, learning to spell is a developmental process. Students make spelling progress alongside learning to write. The needs of the student are at the forefront of the teaching and learning process (Ministry of Education, 2003). Clay (1991) refers to this knowledge of a student's needs as "where the frontier of learning is for any one pupil on a particular task" ( $p$. 65). The unique learning needs and developmental process of each student are acknowledged in The Report of the Literacy Taskforce (Ministry of Education, 1999) and Effective Literacy Practice (Ministry of Education, 2003), who do not recommend prescriptive methods or a pre-determined recipe for teaching.

The developmental process of learning to spell takes several years, with students moving through sequential stages, progressing at different rates (Beers \& Beers, 1991; Gentry, 1991; Jackson, Konza, Ben-Evans, and Roodenrys, 2003). These stages may not be linear and some students pass through them quickly. Also, students with learning difficulties may stay at a stage and not pass to the next (Jackson et al., 2003). As spelling is developmental, students should not be held accountable, for all their spelling being accurate, as may be expected from adult's spelling (Gentry, 1991). Spelling is a code that takes time to learn and it is several years of schooling before the language used in writing is produced as well as it is in speech (Bereiter and Scardamalia (1987). During the process of learning to spell strategies assist development. 


\section{Strategies for spelling}

We use strategies to plan for all facets of our life. Through use of strategies, people locate, interpret, transform or respond to information. Although we each strategise differently, some strategies are more useful in problem-solving than others, at any one time (Clay, 1991).

Students use strategies as they think about spelling the words they write. Spelling can be viewed as a series of problems that can be solved with strategies (Phenix et al., 1991). Without strategies, knowledge is "brittle" (Slamon and Perkins, In Bruning, Schraw \& Ronning, 1999, p. 8). Therefore, a repertoire of strategies that uses knowledge of the written code to problem-solve, is required for successful spelling (Bruning, et al., 1999; Ministry of Education, 2003).

Phenix et al. (1991) use the metaphor of a road map to describe the process of spelling. They explain that using spelling is like finding your way around a strange city with a road map, knowing a few basic principles. The basic principles in the "road map" of spelling are the alphabet and sound principle, or orthography, along with the function and meaning principles, known as morphology. If students are taught to use a repertoire of strategies to control and manipulate knowledge of the spelling system or code, they have a good chance of being accurate. However, "memorising a map of a city you have no intention of visiting would be an impossible task" (Phenix et al., 1991, p. 26) and a waste of time. Therefore, the decisions made about the knowledge and strategies to teach, need to be based on what the student needs to learn.

Students strategise using three main sources of information as they attempt to spell words. The first strategy is the accessing of visual memory. The second and third are the phoneme-grapheme relationships and spelling patterns also known as 
phonographic strategies, and the third is morphological strategies, often known as rules (Ministry of Education, 2010a).

\section{Visual strategies}

The first strategy, visual, is used by students to recall known words from memory. Words learned through visual strategies need to be frequently used so that they pass into long-term memory (Phenix et al., 1991). The words remembered and used correctly in early writing tend to be personal and high frequency words. As Phenix et al. (1991) point out, "memorising a map of a city you have no intention of visiting would be an impossible task" (p. 26). Therefore to expect all words that may be required in writing, to be memorised, would not be useful to the students for their writing. Not all words that a student will need in their writing will be able to be committed to memory (Phenix et al., 1991). Therefore, if words being learned can be linked to other known words, students will begin to combine visual strategies with the use of spelling patterns, conventions and rules.

Phonographic strategies

The second strategy, phonographic, draws on phonological and orthographic knowledge. Phoneme-grapheme relationships are the relationships between spoken sound units and the written symbols that represent them (Ministry of Education, 2010b). The sounds are heard first and then the letters are matched to the sounds (sound to letter), through selection of the graphemes to represent the phonemes. These may be individual letters or clusters of letters. Students are often taught that letters make sounds and this is confusing and not helpful in developing knowledge of English spelling (Allcock, 2006). Teachers need to teach the concept that alphabet letters represent or write sounds. 
When phonetically inaccurate errors are made, phonemic (individual sound) knowledge may be limited or the "store of options" (Brann, 2004, p. 13) may not be correctly used.

Students who have difficulties with hearing or speech are likely to find use of phonographic strategies more of a challenge. With limitations on hearing the sounds, matching the phonemes with the graphemes will be difficult. Local speech therapists, Brown and McLean (2010) raised this as a concern, pointing out that children with speech difficulties are at a high risk of literacy failure. When teaching students with hearing or speech difficulties, reliance on teaching the hearing of sounds will put them at a disadvantage.

\section{Morphological strategies}

A third strategy, using morphology, often develops in students later than the previous two strategies, as the writer learns more about the structure of written English. Morphology is the study of function or meaning of words and is often described as spelling rules (Brann, 2004; Ministry of Education, 2010a; Phenix et al., 1991). It is more likely that when this strategy is used, it is combined with visual or phonographic information. Brann (2004) believes that sound and letter patterns gradually merge with meaning and grammar information.

\section{Awareness of strategies}

The awareness of relevant knowledge and strategies, enables students to deliberately apply and control their use. Brann and Hattie (1995) state that proficient spellers can generate more correct spellings for unfamiliar words as well as retain more stored words. It is likely that proficient spellers have a greater awareness of relevant knowledge and strategies. 
Students need to be taught that spelling is not a memory activity but rather a thinking activity (Phenix et al., 1991). Being able to think and articulate what they know and can do, helps students to problem-solve new challenges. This thinking about their knowledge and strategies is described as meta-cognition (Ministry of Education, 2003).

\section{Meta-cognition}

Meta-cognition refers to two parts of learning. The first is knowing about one's own thinking and the second is the ability to regulate thinking. In regulating thinking, a person becomes more aware of their abilities and more strategic in problem-solving (Bruning et al, 1999). Clay (1991) calls this development of problem-solving, as an “inner control" (p. 327).

Meta-cognition is like the "mission control" of our thinking (Bruning, et al, 1999, p. 95). Use of meta-cognitive awareness assists students to self-monitor learning, think about learning processes, and talk about their own learning, and what they know. Through being more strategic, students can say when, how and why they use a strategy (Bruning et al, 1999; Department of Education Tasmania, 2007; Dickie, 2008; Ministry of Education, 2003). Students become more meta-cognitively aware through using their own strategic knowledge (Bruning et al., 1999).

When constructing new words, a meta-cognitive problem-solving approach enables students to use a "network of strategies" (Clay 1991, pp. 326-327) to crosscheck one source of information with another. The processes of combining strategies, is what Brann (2004) describes as "coordinating the systems" (p. 5). A good speller is not a person who is able to memorise the most words but a person who is able to "figure out the logic of words" and is able to "construct them as needed" (Phenix et al., 1991 , p. 18) through a problem-solving approach within the context of writing. 
Being automatic with processing is essential to good strategy use, enabling the writer to concentrate on the writing content and higher order learning (Bruning et al., 1999). Acquiring automaticity in accessing successful strategies requires metacognitive awareness. When systems are not coordinated, students resort to weak and inefficient strategies (Brann, 2004).

\section{Daily writing and use of teacher feedback}

When spelling is regarded as a skill of writing and taught within the structure of the classroom writing programme, knowledge and strategies are more likely to be transfered into use in problem-solving new words (Croft, 1998). Teacher assistance using feedback is required for the transference into continuous writing (Clay, 1993; Croft, 1998).

When teachers provide opportunity for daily writing, there is more time for the teacher to give feedback. Feedback is information given to work towards closing the gap between what students currently do and what they aim to do. Feedback can emphasise whether the strategy was successful or not and why, and how and why a strategy is useful (Allcock, 2006; Bruning, et al., 1999).

Daily writing affords an opportunity for the student to start to become independent in his or her own monitoring through use of teacher feedback. "Once a week writing leads only to red-lined pieces, since this is the only access a teacher has to the children" (Graves, 2003, p. 194).

Feedback can also be given by people other that the teacher such as class peers, or another adult providing they are clear on the learning intentions, such as the strategies being focussed on.

Smith (2010) raises an important point about teacher feedback. When encouraging self-monitoring, we need to have students guided to find the problem 
rather than the teacher doing so. She notes that fixing errors before assisting learners to find their own errors is common practice, though not useful in developing independent monitoring. Helpful feedback such as the raising of a question by the teacher, can lead to identification of a problem to work on fixing.

When students' errors are regarded as "spelling attempts" (Brann, 2004, p. 6) there is more regard for their use as learning opportunities. Students' spelling attempts can give teachers useful information about students' cognitive processes. Through observation of students' risk taking and their use of strategies to attempt unknown words, decisions can be made about the focus for teaching programmes. A judgment can be made as to whether the student has the necessary phonemic awareness and spelling pattern skills (Allcock, 2006). Deliberate teaching can meet identified next steps (Allal, 1997; Brann, 2004; Ministry of Education, 2003; Phenix et al., 1991).

Identifying specific needs assists greatly with tailoring teaching practices and sustaining achievement (Lai, McNaughton, Hsiao, Mose, Hall, Knight et al., 2010). When errors or spelling attempts in students' writing are analysed, feedback can be specific to the identified needs, based on the learning intention with a view to closing the gap (Brann, 2004; Clarke, Timperley and Hattie, 2003; Vercauteren, 2008). Through "deliberate acts of teaching" (Ministry of Education, 2003, p. 78) students' knowledge, strategies and awareness of the written code are extended.

\section{Approximating in draft writing}

A successful spelling programme is founded on plenty of opportunity to write on a range of topics. A rich writing programme provides opportunities to use the many workings of English spelling (Smith et al., 1997). When there are frequent opportunities to write in continuous text, quality improves. Through writing production, 
spelling knowledge and strategies can be applied, with proof-reading being taught as part of the process (Gentry, 1991).

The attempting of unknown words, allows students to demonstrate their use of phonographic and morphological spelling strategies. The process of construction of words is often known as approximating and is sometimes referred to as inventing the spelling words. Through use of approximating unknown words, the student can engage in writing the message and the thinking process. The less desirable alternatives to use of approximating could include students spending time deliberating on the unknown word, writing an easier alternative, or stopping to find the correct spelling from a source such as a dictionary or a more knowledgeable person.

Approximating is useful in encouraging use of a wide vocabulary through trying out new words. It also provides opportunity for strategy use. Encouraging students to "have a go" at writing new words before seeking help will foster awareness and use of developing strategies (Ministry of Education, (2003, p. 147).

Use of approximated or invented spelling should be viewed as part of a developmental process of learning to write (Gentry, 1987; Hood, 2000). Students pass through stages toward correct spelling similar to how a child moves from rolling to crawling to walking. Just as we should be concerned if a child was crawling at age nine we would also be concerned if a student is still inventing all spellings when they should be able to spell the words accurately. By the end of Year 1, students should be able to write about 30 sight words through the regular use in reading and writing. There should be little inventing of spelling by age nine or ten (Hood, 2000). Frequently used words must quickly become part of the student's repertoire of known words spelt correctly, that students can quickly access visually. 
If a student writes a word incorrectly too often, the incorrect spelling is reinforced into sight memory (Allcock, 2006). Therefore students need to become aware that they should, as much as possible, spell the words in their writing correctly, particularly frequently used words, but not at the expense of writing to express a clear message. Too much emphasis of correctness in the draft stage, can reduce the focus on the message and students may be "unadventurous" (Ministry of Education, (2003, p. 147) in their writing.

\section{Risk taking}

Some students are not keen to take risks, and they make choices to use easier words rather than try one they are unsure of. When a student will not take risks in trying new words, the vocabulary, complexity and length of the writing may be affected (Graham et al., 2006). Writing quality and quantity could be limited, resulting in less practice in the use of more advanced writing skills (Allcock, 2006). Graves (2003) notes that self-diagnosed poor spellers focus on their spelling in the draft at the expense of content, impacting on the quality of the writing.

Writing a small quantity, writing easy 'safe' words, repeating known words rather than varying vocabulary, all contribute to a self perpetuating situation of a lower achieving writer (Jackson et al., 2003). As discussed previously, allowance of risk taking through approximating words provides opportunities to try out spelling strategies, particularly the generalising of information from known words to the new words. Licence to try out words, gives opportunity to problem-solve. "They need freedom to test and modify their hypotheses about spelling" (Gentry, 1987, p. 27).

\section{Instructional Match and the Zone of Proximal Development}

Knowing where the "frontier of learning" (Clay, 1991, p. 65) is for any one student is a challenge. Identifying a student's "instructional match" (Ysseldyke et al., 
2003, p. 5), and applying appropriate instruction is best done through analysing spelling errors in the student's writing.

The learning that can be enabled with support is often referred to as the "zone of proximal development". This is defined as "the distance between the actual development level when the student is independently problem-solving and the level of potential development when problem solving is under adult guidance, or in collaboration with a more capable peer" (Vygotsky, 1978, In Tudge, 1990, p. 157). Appropriate guidance at the zone of proximal development is often referred to as scaffolding (Vygotsky, 1962, In Clay, 1991, p. 65). Peers can be made use of in the classroom to support scaffolding, through the pooling of meta-cognitive knowledge and strategies (Bruning et al., 1999).

\section{Spelling lists}

It is common practice that primary school spelling programmes include groups of words in personal spelling lists for students to learn. Lists make up part of homework, with expectations that words will be learned at home. The Literacy Learning Progressions (Ministry of Education, 2010a) states that by the end of Year 4, students should be using their visual memory to spell personal vocabulary and most of the high-frequency words in the essential lists 1-4 along with many words from lists 5-7 (Croft et al., 1998, See Appendix O). A similar standard is written in the table of expected levels of the asTTle assessment (Ministry of Education, 2010e). It could be interpreted that in order to ensure these expectations are met, the most efficient way of ensuring these words are learned is to transfer the essential lists directly into students' personal lists. Croft (1998), who compiled the essential lists argues that spelling is a skill best learned in the context of writing. Croft believes there is a place for specific learning of selected words provided they are necessary for the 
child's writing in the immediate future. The core words students need to learn, should first come from students' own writing, from errors being identified as part of the writing process. According to Croft, if students have not mastered the high frequency words through their own writing lists and through the use of the words in writing, along with word study and vocabulary extension, then towards the end of the student's fourth year, the 300 words (in the essential lists) that make up three quarters of children's writing need to be mastered.

Hood (2000) argues too that the first place words should be selected from, is a students' own writing. Hood discusses his own childhood memories, of learning spelling from lists of unfamiliar spelling words. He found the unrelated words were difficult to learn. He recalls, "The words I had were all strangers." (p. 74). Although Hood advocates the use of a spelling homework learning system, he suggests that words selected to learn, are those that students have attempted to write. These words are familiar to the student and in their vocabulary, and consequently will be used again in the near future by that student. Teachers may be dubious, thinking some students will not extend their spelling vocabulary if words are only selected from personal errors in writing. Hood has some suggestions for this issue. One suggestion is to extend students' language and vocabulary so that students will want to use new words in their own writing. He suggests that words can be supplemented from the essential lists but the first place should be from students' own errors. Hood also points out that if the words on the lists have been tested and signed at home, there may not be a need to use time on a re-test at school.

Many people question whether words learned for a Friday test are spelt correctly in the student's writing when needed, stating how disappointing it is for all, when students still cannot remember correct spellings in their continuous writing 
despite conscious effort to learn the words on their list (Brann, 2004; Reason and Boote, 1994; Smith et al., 1997). "Nothing has been more ubiquitous in U.S. schools than the spelling test on Friday, despite the fact that most students do quite well on Friday only to misspell some of the same words on Monday" (Invernizzi and Hayes, 2004, p. 8). Spelling tests do not give us a true measure, as students may get high scores in tests, but "the ultimate test is what the child does under 'game' conditions" (Graves, 2003, p. 194). The discrepancy between the two contexts may be because in schools, spelling may be tested far more than it is taught, with guidance on how to learn and strategise being minimal. Rote learning of a word is only useful if the words are used frequently enough to pass into long-term memory. When a student is able to use the learned word correctly in writing, then that is the "ultimate test of success" (Reason et al., 1994 p. 561).

A danger of learning words in isolation out of context, is that students may think that memorisation is the only method of learning to spell to the detriment of using other strategies that make use of problem-solving and generating new words (Allal, 1997; Phenix et al., 1991).

Reason et al., (1994) suggest that a more effective method of making a relevant list of words is to get the students to co-construct with the teacher, relevant lists based on spelling needs and prior knowledge of words. This co-construction assists teachers with making an "instructional match" (Ysseldyke and Christenson, 2002) as teachers gain information on whether students can generalise from their knowledge to create new words.

\section{Good spellers, poor spellers}

Many people refer to good spellers as having good memories and poor spellers having poor memories. With this goes the assumption that spelling is 
primarily a task of memory (Beers et al., 1991). Judgements are made on students about whether they are good or poor spellers through the view of their ability to reproduce words from memory (Brann, 2004). This type of judgement does not take into account how students are attempting to spell through strategy use. If the emphasis is predominantly on what can be memorised and accessed visually, students and teachers will not value meta-cognitive awareness. The use of phonographic and morphological strategies and the merging of these strategies to problem solve may be lost if teachers have a narrow view of a good speller.

\section{Use of computers for writing and spelling}

E-learning which is defined as learning supported or facilitated by ICT, (Ministry of Education, 2007, p. 36) may enhance spelling learning opportunities in several ways. Firstly by providing tools that can take learning further, secondly, in the way ICT assists in creating a supportive learning environment, and thirdly in the way it facilitates shared learning.

Use of a computer as a writing tool can benefit writing quality. Drafting and redrafting written work on a computer can be a helpful alternative to writing and revising by hand (Ager, 2003). Work can be revised quickly without the manual labour of rewriting. Meaning in writing can be concentrated on (Ministry of Education, 2003). Ager (2003) suggests a way of managing the use of computers in class writing, with each student taking a turn to work on a project from drafting through to publishing.

Use of a computer to compose, can be helpful for less able spellers. Through the use of self-correction options as the student is composing, risk taking can be encouraged. Through providing this scaffolding, students are assisted with the task of spelling and they can put their energies into generating ideas, forming language and organising information (Phenix et al., 1991). 
Small groups or pairs of students can work collaboratively on a computer. This can create a supportive learning environment where learning is shared and scaffolded, as peers teach each other. Collaborative work with two or three students working on one computer, can provide an environment where the group provides the scaffolding they each need.

The spell-checker tool can assist with monitoring and checking spelling as incorrect words can be identified. Clicking on the identified word can give students options to select from for possible words to correct it (Ager, 2003).

Jackson et al., (2003) advocate the use of an electronic spell-checker even for when students are manually writing their drafts. In their study the teaching and use of the spell-checker had a marked effect on the students' spelling for students with marked spelling difficulties, providing opportunities for increased accuracy.

Certainly both word processing and spell-checker tools are becoming an increasing available option, with benefits for increasing accuracy and consequently the opportunity to work on the "deep features" (Ministry of Education (2010e) of writing.

\section{Summary of literature}

Chapter 2 has discussed ideas about teaching spelling of English, with a particular focus on spelling teaching and learning within New Zealand primary schools. Spelling is a tool of writing. Therefore the emphasis in this study is viewing spelling within the context of writing in the classroom.

The use of meta-cognitive awareness to "figure out the logic of words" (Phenix et al., 1991) is thought to be necessary to strategise effectively. The three main strategies students use to spell words include visual, phonographic and morphological. These strategies were discussed, along with the notion that strategies 
can be used singly or in a combination to problem-solve new words. It is thought that strategies used in combination may be more effective.

The common belief is that learning to spell is a developmental process. Therefore it is widely accepted that there will be errors in students' daily writing as students take risks in attempting new words. Through making use of approximating in daily writing, students learn to strategise in their spelling. They are also free to use new vocabulary and develop ideas without the fear of being wrong. Teachers can analyse students' attempts and plan for deliberate teaching of strategies at the students' instructional match.

The practice of providing spelling lists of words for students to learn was discussed, along with the source of the words for the lists. Most literature point to students' own errors in their writing as being a relevant place to source words for students to learn.

There was a discussion of the place of computers in the process of spelling and writing, with computers now being used extensively as a communication tool.

\section{Current gaps}

The Report of the Literacy Taskforce (Ministry of Education, 1999) stated in its aim that "by 2005 , every child turning nine will be able to read, write and do maths for success" (Ministry of Education, 1999, p. 4). This goal and the recommendations of the Taskforce effected changes in resourcing, including provision of publications and professional development to schools. Included in. the many new documents produced to assist teachers with teaching students literacy skills, more explicit measurements are now in place to assess student achievement.

However, some students, after three years of schooling are behind expected levels. If it is acknowledged that the student needs to be at the centre of learning 
decisions, drawing on the student voice and expertise will be useful. Students' explanations may give an insight of how the students themselves explain their use of strategies to spell words when they write. It may give an insight into how aware they are of their abilities and how strategic they are in problem-solving (Bruning et al., 1999).

When considering how and why some students have literacy difficulties, it is useful to find out about the strategies used by students who are not having difficulty. Successful spellers may strategise more efficiently (Brann, 2004; Snowling \& Stackhouse (1996). Therefore, through an in-depth case study of a small group of students this research will investigate knowledge and strategies students use. By talking to students who are successful we can find out how they strategise. By selecting two groups of students, those achieving at expected level and those achieving below expected level, their explanations can be compared to search for differences and similarities of strategy use. Findings about what teachers believe are important to teach will be triangulated with the students' views.

The Year 4 students selected for this study are aged eight, one year younger than where the the Literacy Taskforce Taskforce placed its focus for success. However, having attended school for three years, these eight year olds are at a crucial time in their schooling. Those students still working within Level 1 in writing and spelling are already falling behind their peers and at risk of not catching up. Comparisons between data from the two groups may provide us with direction towards how to teach those that find spelling difficult.

Chapter 3 describes the methodology for this study. It outlines the research questions and the theoretical base that lead to the reasons of for this type of qualitative research. 


\section{CHAPTER 3}

\section{Methodology}

\section{Introduction}

Chapter 3 outlines the methodology used in this investigation. It outlines the research questions and the theoretical framework and then it describes the participants and procedures for gathering and analysing data.

This was a qualitative case study, which investigated strategies that Year 4 students used when spelling in the context of classroom writing. The strategies of lower achievers were compared with those of average achievers. These strategies were then compared with teachers' beliefs about the knowledge and strategies that are important in spelling.

In qualitative research such as this, the researcher attempts to be as unobtrusive as possible in order to have little influence on the behaviour studied at the time. This research report is narrative with rich descriptive detail and direct quotes from the participants (Johnson \& Christensen, 2008).

The intention of this investigation is to give an insight through student voice and teacher perspective about spelling strategies that have been successfully used to spell words in the context of classroom writing, and to identify gaps that may be impacting on some students' progress. Knowledge of successful strategies may assist in improving classroom spelling programmes. Therefore a qualitative study is a useful approach to gain an insider view of the impact of programmes on student achievement. Qualitative data communicates peoples's experiences in their own words (Patton, 2002). Qualitative research is situated in the natural setting. It involves the study and collection of empirical materials that describe meanings and tell stories (Denzin \& Lincoln, 2005). 
In a case study approach to qualitative research, methods of data collection are through interviews and observations along with examination of documents (Johnson \& Christensen, 2008). The choice of data gathering for this study was through use of all these methods. Transcripts provide a record of interactions in interviews and and are reliable records for researchers (Silverman, 2001). Detailing interviewing is a way of gettting close to the subject's perspective (Denzin \& Lincoln, 2005).

Miles and Huberman (1994) point out that through early analysis of qualitative data, the researcher can be lead towards collecting new data to fill any gaps that emerge and useful changes can be made to data collection. This research included a pilot study and analysis of the data from the pilot lead to refining the methods. The sources of data for the main study were interviews and student documents. Interviews were transcribed. Student documents were used as a vehicle to personalise the interviews and analysed for statistical data.

\section{Research Questions}

1. What are the knowledge and strategies used by Year 4 students who are achieving below expected level, when spelling words in their writing?

2. What are the knowledge and strategies used by Year 4 students who are achieving at expected level, when spelling words in their writing?

3. How do the strategies compare between the two groups of students?

4. What are the knowledge and strategies that teachers believe are important, and how do their beliefs compare with the strategies students use?

\section{Theoretical Framework}

Learning to spell is a developmental process like learning to talk and its acquisition is progressive alongside learning the skill of writing. Spelling can be viewed 
as a series of problems that can be solved through use of strategies. The encouragement to take risks using approximations for unknown words provides opportunities for students to practise spelling strategies. The development of students' meta-cognitive awareness, as reviewed in the literature, helps students to become more strategic in their problem-solving of new words (Bruning, et al., 1999; Phenix et al., 1991).

When considering how and why some students have literacy difficulties, it is useful to find out about the strategies used by their more successful peers. (Brann, 2004; Snowling et al.,1996). By talking to students about their successful strategies we can find out how they use meta-cognitive problem solving to assist with strategy use.

Research that seeks to understand students' awareness through their own voices provides insider perspectives that would otherwise not be present in a study that did not include student thoughts. Therefore, through an in-depth case study of a small group of students, this research investigated the knowledge and strategies used by students.

The strategies were compared through cross-case comparisons, between the data from successful and that of the less successful students. Data were triangulated through comparing the teacher beliefs with the strategies of the lower-achieving and average-achieving students. Triangulation provides for differing perceptions to clarify meaning and also gives opportunity for different perspectives to be represented (Stake, 2000).

\section{Setting}

This is a qualitative in depth case study of a small group of students and their teachers in three primary schools that are situated in suburbs in a New Zealand city. 
These schools work together in a Cluster Schools' Improvement Project (Ministry of Education, 2010c). All the interviews were conducted in the schools.

\section{Participants}

Teachers

The nine teacher participants consisted of three Year 4 teachers (one from each school), and six teachers of junior students, Years 1-3 (two from each school).

\section{Students}

The student participants were from the Year 4 teachers' classes, two Year 4 boys and two Year 4 girls from each of the three schools. This made a total of 12 participating Year 4 students, six boys and six girls. Criteria for the students were that they had attended New Zealand schools for at least three years continuous education, and spoke English as their first language. They had not been identified with any major hearing loss or visual difficulties. If students with identified hearing or visual dificulties had been included in the sample, these difficulties could have been variables impacting on the results. Half the students had been assessed by their schools as achieving within the Level 2 range on the asTTle asssessment, and half of the students had been assessed by their schools as achieving below Level 2 on the asTTle assessment (Ministry of Education, 2009d) scores that had been administered by the schools in March 2010.

\section{Strengths and limitations}

A strength of this research is that it collected "rich descriptions" (Denzin \& Lincoln, 2005, p. 12) of in-depth insider viewpoints through students' and teachers' own voices. Students and teachers provided their own views and explanations of strategy use in spelling. Research such as this provides more in-depth knowledge from students than a teacher can gain while they are teaching in a classroom setting. 
Limitations of this research are that it is non-experimental and as it is a small study, it cannot be generalised to all New Zealand Year 4 students, or all Year 4 students in the cluster of schools from which the sample was drawn.

\section{Ethics}

Ethical approval was given through Victoria University Faculty of Educational Ethics Committee. Permission was sought and accepted from participants before fieldwork commenced.

\section{Threats to validity/bias}

There was a chance that there could have been confusion between my role as a researcher and my role as Research Teacher: Learning and Behaviour (RTLB), as some of the teachers may have worked with me in the past in the course of my work. Therefore it was important to separate this research from my work as an RTLB. This separation was assisted by my not currently working in the schools as an RTLB during the period of the research. To clarify my role, I attended a staff meeting at each school where I explained to the teachers, what my research would involve.

It is important for the interviewer to gain rapport with the participants so that the relationship fosters the want to participate in the process (Bryman, 2004). This relationship building was important for the teacher and the student participants. As the students were young children, and I was a stranger to them, it was crucial to make a special effort to establish and continue to build a good working relationship with them.

\section{Confidentiality}

Confidentiality was placed at the forefront of my research and was written into my letters of explanation about the study to all the participants (See Appendices A to 
$H$ ). At the time of seeking permission from the teachers, I sought to establish a relationship of trust and gave the opportunity to clarify any questions the teachers had. The participating students were also given clear explanations about confidentiality at the time permission was sought, and a trusting relationship was built during the interview sessions. Pseudonyms were used for student participants to protect confidentiality. Teacher quotes were anonymously reported.

\section{Consent}

All adult and child participants gave informed consent. Participants were given the right to accept or decline participation, and could also withdraw consent up to the time of data analysis. The process was explained in the letters and consent forms (See Appendices A to H).

\section{Procedure for selecting participants}

Through professional contacts among the cluster of schools, I approached three principals and asked if they would be willing for their schools to be part of the research. The three principals that were approached all agreed. Written permission was sought (See Appendix A: Letter of explanation for principals; and Appendix B: Consent form for principals). The principals discussed the proposed research with their staff and sought willing staff participants.

Pilot study

The pilot was conducted during the month of March 2010 over a period of two weeks. One school was selected to be part of the pilot study as well as the main study. The principal approached two teachers for the pilot and permission sought (See Appendix C: Letter of explanation for teachers; and Appendix D: Consent form for teachers). The principal and I selected four students who were attending Year 4 to be participants for the pilot. Parents were contacted and written permission sought 
(See Appendix E: Letter of explanation for parents; and Appendix F: Consent form for parents). Written permission was sought from the four selected students for the pilot study (See Appendix G: Letter of explanation for students; and Appendix H: Consent form for students).

Main study

The main study was conducted during April and May 2010. Each of the principals approached three teachers to participate in the main study. One teacher participant from each of the schools was a teacher of Year 4 students. The other two teachers in each school taught junior students (Years 1-3). Written permission was sought from the three teachers at each school (See Appendix C: Letter of explanation for teachers; and Appendix D: Consent form for teachers). The teachers of the Year 4 students assisted me with selection of students who fitted the criteria for the main study. Parents of students selected for the main study were contacted and permission sought (See Appendix E: Letter of explanation for parents; and Appendix F: Consent form for parents). When the parents had returned their written permission, students were contacted in the schools. In the groups of four students, I explained the research and invited students to participate. The students agreed verbally and gave their written permission (See Appendix G: Letter of explanation for students; and Appendix $\mathrm{H}$ : Consent form for students).

\section{Internal Validity}

Care was taken in setting questions and with interview techniques (Johnson et al., 2008). To control for factual accuracy, the interviews were taped and transcribed. To control for accurate portrayal of meaning given by all participants, they were asked for clarification, as it was required. All interviews were audio-recorded and later transcribed. Teacher participants were given transcripts of the interviews for 
checking. Student interviews were transcribed and individual comments recorded for analysis. As these students were young children, aged eight, there may have been challenges for them reading the transcript. Therefore instead of returning transcripts to students, I sumarised the main points at the end of each interview session and also sought clarification, during the interviews. This resulted in students clarifiying their views at times. The researcher analysed all the data.

\section{Research design}

Pilot

A pilot study gives the opportunity to check whether procedures and methods will work and identifies faults or weaknesses. It needs to be built into the time frame for the study. The data are often not used in the final analysis as data collection tools may have been adjusted (Walsh 2001). As a result of the pilot, I made adjustments to the interview questions to clarity questions with the view to adding to information that would be gained. I also made changes to the data collecting procedures. The pilot had included observing the student participants working on their writing in class. This did not add anything to my data and was an extra time commitment for me. It also added to teacher load. Therefore I did not observe students in class for the main study.

\section{Main study}

I worked in each school over a two-week period. During the two-week period, I interviewed the four students and the three teachers. This process was repeated in each of three schools.

The teachers were interviewed individually at a time that suited each teacher (See Appendices L and M). Each teacher interview took approximately one hour. 
The timing of student interviews was in consultation with teachers, in consideration of the needs of students and their learning in the classrooms. No recreation or lunch break times were used for student interviews.

The first student interview consisted of working with the group of four students on the asTTle writing sample (See Appendix N). The students were given the writing topic. There was a five-minute discussion about the writing topic, between the students and I. The students were given five minutes to plan their writing, then 40 minutes to write the story.

The students were interviewed in pairs on two further occasions, firstly on the same day that the writing sample was completed. (See Appendix I: Interview Schedule 1 for students). The writing sample was used as a vehicle for students to answer the questions relating to how they spelt the words they needed. The pairings of students usually consisted of two boys together, and two girls together. The reason for the gender groupings was to assist them to feel as comfortable and at ease as they could when being interviewed.

On a following day, the students were interviewed again in pairs (See Appendix J: Interview Schedule 2 for students; and Appendix K: Interval Schedule 3 for students). Samples of the students' class writing along with the writing sample conducted on the first interview day were available as an aid to prompt discussion. Instruments

The instruments consisted of:

Appendix I: Interview Schedule 1 for students Appendix J: Interview Schedule 2 for students Appendix K: Interview Schedule 3 for students Appendix L: Interview Schedule 1 for teachers 
Appendix M: Interview Schedule 2 for teachers

Appendix N: AsTTle writing test

A voice recorder.

Measures

In structured interviews, all interviewees are given the same questions so that the replies can be aggregated and reliability is achieved as the responses are from identical cues (Bryman, (2004). In semi-structured interviews the questions can lead into a "guided conversation" with the interviewer asking for further clarification where needed (Walsh, 2001, p. 65). Interviews in this research were semi-structured in that the questions were identical, with further probing questions being added to clarify meaning and gain more information where it was available. This was particularly useful to capture teachers' knowledge and interests. Data were gathered through the semi-structured interviews with exploratory questions, and through the analysis of students' writing. In depth information was gained about students' and teachers' beliefs and understandings about spelling within the context of the students' writing,

\section{Data Analysis}

In case studies such as this, that involve multiple cases, each case is usually examined in total. Then the different cases are compared in a cross case analysis for similarities and differences across cases (Johnson \& Christensen, 2008). Case study research does not manipulate variables, thereby as much as possible not disturbing the setting of the research (Walsh, 2001).

In order to prepare the data into an "analysable form" (Walsh, 2001, p. 83), it needs to be coded and collated. Coding is an important part of data analysis. It involves identifying and categorizing useful data. All data needs to become familiar 
before decisions about codes are made. Codes can be based on the literature, or driven by the emerging data (Gibbs, 2007, In Dahlberg \& McCaig, 2010).

Richard and Morse (2007, In Dahlberg \& McCaig, 2010) describe three varieties of coding, namely descriptive coding used for factual details, topic coding used to identify all data that can be grouped together around a topic, and analytic coding which categorised the data.

In this study, emerging information of significance was noted, as well as similarities, differences, patterns, themes and trends between students, and between students and teachers. Through examination of the literature and the data, it emerged that topic and analytic coding would both be used to analyse qualitative data.

Descriptive coding was conducted to collate factual details such as number of words students spelt correctly and number of words written in the writing sample. Statistics were collated in simple tables. These statistics were used for comparison between the students, and triangulated with the qualitative information from interview data.

\section{Grouping the students}

For the purposes of the research I grouped the students into two groups using the schools' asTTle (Ministry of Education, 2009d) test score that had been administered by the schools in March 2010.

Group A were those students who, in March 2010, scored within the Level 2 range in asTTle (Ministry of Education, 2009d) for their 'best fit' in writing and spelling scores.

Group B were those students who, in March 2010, scored below Level 2 in asTTle (Ministry of Education, 2009d) for their 'best fit' in writing and spelling scores. 
The students were interviewed in pairs. The paired interviews often involved one student from Group A and one student from Group B. Data from each student were separated when transcribed.

Conventions for recording results

During discussion of results direct quotes were made of students' and teachers' comments to illustrate understandings and beliefs. Quotes have been written in italics and enclosed in quotation marks.

When words or groups of letters are discussed, they have been written in bold. When there is a discussion of incorrect spelling, the student's spelling of a word is written followed by the correct spelling. For example, verry/very.

\section{Profile of the participating students}

All students were age eight at the time of the study. Their birth dates ranged from May 2001 to March 2002. Of the 12 students, three identified as Māori, one identified as Pasifika and eight identified as New Zealand European.

For the purposed of this research, the A Group were referred to as 'the average achievers', 'at expected level', and the 'more successful writers'. The A group consisted of four girls and two boys: Olivia, Madison, Emily, Chloe, Daniel and Ethan (Pseudonyms used).

The B Group were referred to as 'the below average achievers', 'below expected level', and the 'less successful writers'. The B Group consisted of two girls and four boys: Elizabeth, Samantha, Joshua, Anthony, Matthew and William (Pseudonyms used).

\section{Results}

The results are representative of insider viewpoints and were discussed in this narrative report. 
Chapters 4 consists of the results from the student interviews, analysis of the writing samples conducted as part of the interviews, along with discussion about the findings. The chapter answers research questions 1, 2 and 3. Following this, Chapter 5 presents the results from the teacher interviews and makes comparisons with student data. There is discussion of the triangulation of findings as it seeks to answer research question 4 . 


\section{CHAPTER 4}

\section{Results and Discussions - The students' views}

This chapter presents and discusses the results gained from the contributions of student participants. It seeks to answer the research questions 1,2 , and 3 , which explore the strategies and knowledge these Year 4 students use when spelling words in the context of classroom writing. The questions were addressed by the researcher conducting a timed writing sample with the students, viewing class work from writing books, interviewing students about the spelling they had used in their writing, and interview questionnaires. (See Appendix I, J and K: Interview schedules for students).

Information about knowledge and strategies individual to each student participant was gained during the interviews, where the students and I (the researcher) examined their sample of writing (See Appendix $\mathrm{N}$ ) and the students answered questions about the words they wrote (See Appendix I). The students' class writing was also discussed with them at interview time, prompting further discussion about the strategies used to spell the words they had written.

Results from the interview questionnaires (Appendices I, J and $\mathrm{K}$ ) provided information on student beliefs and understandings about spelling in writing. The information discussed in this chapter was gained directly from these sources through the student participants, thus providing an insider view. It offers the perspective of young primary school children's understandings and beliefs about spelling, in their own words.

The student participants were Year 4 students who have been attending school for at least three years, selected from three schools. They consisted of two groups of students. One group of six students, were assessed by their teachers as achieving within Level 2 (Ministry of Education, 2007a) in writing text and spelling 
within written text. This group (named by the researcher as the A Group) is at expected level for Year 4 students. The second group of six students, had been assessed by their teachers, as achieving below the expected level (the B Group). By Year 4, achievement should be within Level 2 in the New Zealand Curriculum (Ministry of Education, 2007). Year 4 students that are working below Level 2 in the New Zealand Curriculum are well below expected level and at risk of not catching up.

Analysis of the data, involved examining the strategies of the below average achievers (B Group) and those of the average achievers (A group). Following this, to answer question 3, I have compared the two groups for trends that show similarities along with differences that distinguish the two groups from each other. The chapter following discusses the results of the teacher participant interviews. It seeks to answer question 4, the teacher participants' beliefs about teaching spelling, and how this compares with the student beliefs.

\section{Meta-cognition}

Learners of literacy need to develop a knowledge base and a repertoire of strategies, which are used together to learn and make use of the written code. Awareness of the relevant knowledge and strategies enables students to control them in a deliberate way. Being able to think and articulate what they know and can do, helps students to problem solve new challenges. This thinking about their knowledge and strategies is described as meta-cognition. Learners who have meta-cognitive awareness self-monitor their learning, think about their learning processes, and talk about their own learning, and knowledge (Department of Education Tasmania, 2007; Dickie, 2008; Ministry of Education, 2003). Brann (2004) suggests that the more information a writer has about a word, the greater the options available and the greater the awareness of the choices available. 
This study sought an insider view to provide explanations of how the students used meta-cognition to "figure out the logic of words" (Phenix et al., 1991). It was found in this study, that when students were faced with a spelling problem, varying degrees of meta-cognition was used, depending on their knowledge and available strategies. The use of a meta-cognitive problem solving approach, lead towards the construction of new words as required. When this happened, one source of information was cross-checked with another, and then knowledge and strategies applied to new situations. The use of meta-cognition was shown to be a factor that contributed to more successful use of spelling within the students' writing. It was clear that the more successful spellers were able to access their repertoire of strategies, to combine more than one strategy to problem solve, and apply their knowledge and strategies to construct new words. The processes of combining strategies, is what Brann (1995) describes as "coordinating the systems" (p. 5). Being automatic with processing is essential to good strategy use to enable concentration on higher order learning (Bruning, et al., 1999). Acquiring automaticity in accessing successful strategies requires meta-cognition. When systems are not coordinated, students resort to weak and inefficient strategies (Brann, 1995).

\section{Strategies used to spell words}

The revised New Zealand Curriculum (Ministry of Education, 2007, p. 52) states that students working at Level 2 will "use a range of strategies to self monitor and self correct spelling". Spelling is often given a focus at proof-reading time, with students asked to find errors and fix them. The Literacy Learning Progressions (Ministry of Education, 2010a) describe the skills that students are expected to have after three years at school. They state that when creating texts, students will use visual memory to spell personal words and high-frequency words, and encode 
unfamiliar words using spelling conventions and rules. When seeking to answer the research questions about the strategies the participating students used, the emphasis is on an examination of the strategies students initially used to access the words they needed when creating their text. It includes what they did in the course of writing their ideas and how automatically they accessed useful strategies through the use of metacognition. However, many aspects of classroom spelling programmes emerge from the data, and are discussed accordingly.

Strategies are ways to relate to known information or prior knowledge and to locate, interpret, transform or respond to information. Although students each strategise differently from each other, some strategies are more useful in problemsolving than others at any one time (Clay, 1991).

Emerging from the data were three distinct categories of strategies the students used to spell words: visual, phonographic and morphology. The strategies are described below.

\section{Visual strategies}

All the students discussed using visual strategies, particularly when recalling known words from memory. Words learned by visual memory need to be frequently used so that they pass into long term memory (Phenix et al., 1991). Visual strategies were most often used to access the common and frequently used words, but they were also used in those words of particular personal interest to a student. An example of using a visual strategy was when Ethan (A Group), who wrote about when he suffered a broken arm. He recalled the word cast from a photo album he had at home, in which there are labelled photos of his plaster cast. He recalled this word from memory and used it appropriately in his story. Generally, visual strategies used singly require little meta-cognition, as the words written have been used or seen 
frequently enough to be stored long-term. However, writers are unlikely to be able to recall from memory all the words they will need to use in their writing, thereby requiring access to other strategies which use spelling conventions and rules.

Phonographic strategies

Whereas reading makes use of graphophonic or letter-to-sound information, spelling uses sound-to-letter information. This sound-to-letter information is described as phonographic (Brann, 1995). In using phonographic strategies, students draw on their phonological and letter knowledge. The sounds are heard first and then the letters are matched to the sounds. An example of the use of a successful phonographic strategy was when Joshua (B Group) wrote nest in his story and explained, "I just sounded it out, nest." (articulated the word). When I asked him, “When you said nest slowly, how did that help?" Joshua replied, "It helps me to find out what letters are in there, and what order they go in." In this case Joshua was able to solve the spelling of the word he needed. However, phonographic strategies alone will not provide all the information for spelling many words accurately and often students who used phonographic knowledge, combined this strategy with visual knowledge through the process of meta-cognition. An example is when Samantha (B Group) wanted to write get. She used her visual knowledge saying "I knew how to spell got, and when I sounded it out, I put e where the o was, and I knew how to spell it." Her use of combining visual and phonographic knowledge gave her the new word. A further combination of strategies can occur if morphological information is added to the strategy use.

\section{Morphological strategies}

When students used morphological strategies they described knowledge of the principles of function or meaning (Phenix et al., 1991). 
This type of information is often described as rules (Ministry of Education, 2010a). Examples of morphology that these participating students used included apostrophes, compound words and tense. Brann (1995) points out that use of morphology develops later in a student's spelling development. The findings in this study back this up, with the students in A Group demonstrating more use of morphology than those in the B Group. These morphological strategies were used in combination with visual or phonographic knowledge through the process of meta-cognition.

\section{Strategies used by Year 4 students who are achieving below expected level}

\section{Introduction to the B Group}

There were six students in the B Group. When they were asked at the interview how good they were at writing and spelling (Appendix K), two students believed they were good at writing and spelling, two believed they were fair at writing and spelling and two believed they were poor at both. Pre-writing planning for their writing sample showed basic picture(s). Planning is useful for organising ideas and generating language for writing (Ministry of Education, 2010a). Their basic picture plans were of limited use for gathering a structure of ideas or for pre-planning of useful words for the writing. The total different words written correctly in their writing samples (Appendix N) ranged from 17 to 34 words for five of these students. The total running words written (correct and attempted) in the sample of writing ranged from 59 to 89 words. Very few non essential list words were written correctly and also very few consonant-vowel-consonant (cvc) words were correct. The sixth student in this group wrote more words, and although assessed by the school as below Level 2, her 
sample showed that she was working closer to the average range than the other five in this group. Her comments however, are included in the B Group data.

\section{Visual strategies used}

The words that were correctly written by the students in this group were mainly one-syllable words. The words were within the group of most frequently used words in the essential lists (Croft et al., 1998). Amongst the common words correctly used, the individual student's writing contained very much each student's own repertoire. There were also many errors made in words that are considered basic words. These are words that will have been provided to these children over their three years of attendance at school in their spelling lists, but were not yet mastered. Words such as my/me, tok/took, soor/saw, sied/said and whse/was were among the incorrect basic words.

There were a few correct words within individual repertoires that were not amongst the most commonly used words. The students' explanations of their recall of the words offered insider views. Elizabeth recalled luge correctly and she reported relating its use to a happy experience, having been on a luge often. Matthew recalled the word game, and he explained that when he performed a 'Google search' he typed car games, army games or pirate games. His frequent use of the word has enabled it to be stored in his long-term memory and visually retrieved. Similarly, Matthew can also recall on and off from labels on a heater, which he sees often. There was a similar story for Samantha with the word room. She had seen it often on the door of a classroom. Of the two-syllable frequently used words written correctly by these students, they were personal to individuals. Another use of a visual strategy to recall a word was in Anthony's spelling of happy, which he recalls he had seen on a television programme. 
The partial recall of words through visual strategies was also demonstrated. Anthony attempted dowen/down and mror/more. He linked words to his experience and demonstrated visual recall of parts of the words. The experience he used was when he downloaded a DVD from a computer. He recalled that the computer asked: 'Do you want more?' His memory of this experience enabled Anthony to try down and more in his writing.

\section{Phonographic strategies used}

Sound-to-letter information was often used. Joshua's strategy for nest was recounted in the introduction of this chapter. Joshua showed use of phonographic strategies for this word. Interestingly, the first explanation he gave at the interview was "I guessed it". However when I prompted him for further information, he explained that he articulated the word and listened for sounds. This is an illustration of a student using an appropriate strategy but not being aware of his/her actions until an adult discussed it with him.

There were examples when Group B had recalled words visually but the knowledge was not manipulated to be generalised to new knowledge through use of word analogies. For example Matthew knew play and way but could not give any other words using his knowledge of these two words. William made some analogies from his knowledge of night and light. He said, "I figured out might". This was a very useful analogy. However, he did not further develop this knowledge for frightened which he wrote as frineted. When I discussed his current knowledge of night and light and how it could be used for frightened, he was surprised but pleased. The meta-cognitive link had to be made with an adult's assistance. This example shows how the gap between what a student knows and what they do not know needs to be bridged by the teachers. Knowing where the "frontier of learning" (Clay, 1991, p. 65) 
is for any one student is the challenge. This "zone of proximal development" (Vygotsky, 1962, In Clay, 1991, p. 65) is where learning can happen with appropriate support.

Students' meta-cognitive awareness was demonstrated with instances when they managed to spell words correctly by combining visual and phonographic strategies. For example, Anthony wrote zoom from his knowledge of zoo. He explained that he had been to the zoo and seen the sign, and combined this visual knowledge with phonographic by adding $\mathbf{m}$ at the end. Another example was when Matthew noted that Carl was a name that he knew and so that confirmed his spelling of car. "Carl has an I on the end." Again this shows combined use of visual and phonographic strategies. A further example is when Samantha used what she knew of spelling the word sheep to help her with asleep using meta-cognition and combining visual and phonographic strategies. She also used a similar combination of strategies when she needed mummy. She identified she was unsure of her attempt but said she knew mum and tried $\mathbf{m} \mathbf{y}$ on the end. Samantha had a useful set of strategies that worked. However she did not use them consistently. For example, she displayed proficiency in using word analogies to substitute a middle vowel phoneme to produce get through knowing got. However this strategy was not yet embedded. With other cvc (consonant-vowel-consonant) words such as put, but and Iot, she was unable to spell them correctly. Samantha displayed some useful isolated knowledge and the challenge is to use her available knowledge and her practised use of strategies for new problem-solving. She requires scaffolded practise of strategies in her writing. That is the challenge of "instructional match" (Ysseldyke et al., 2002). 
Phonetically inaccurate spelling was a frequent occurance with these lower achieving students. Brann (2004) states that when phonetically inaccurate spelling occurs, sound analysis is not being properly employed or the "store of options" (p. 13) are not being applied correctly. Examples were hit/hat fome/from, cras/crash nexe/next, frirst/first, mror/more, hate/had, sau/say and bot/but. When these types of phonetically inaccurate errors are made, phonemic knowledge is limited (Brann, 2004). When the students discussed the strategy they used for these attempts, they explained that their strategy was 'sounding out' or 'guessing' the word. When asked, 'What do you usually do when you can't spell a word?' (See Appendix K) $50 \%$ of these lower achieving students chose 'sounding out' and $33 \%$ chose 'guess' as one of two choices. A clear explanation of what students mean when they refer to 'guess' was not gained in the interviews.

I questioned these lower achieving students about their knowledge of the words that they had personally written correctly in their class writing (See Appendix J). This provided further information about the phonological knowledge they used. Most students were able to give the beginning, middle and end letter of a consonantvowel-consonant (cvc) word (tending to give the letter, not the sound) and usually could give the number of syllables in a word. They did not show understanding of the amount of individual sounds (phonemes) in a word. Without phonemic knowledge of the words, students are unlikely to be able to use sound analysis to generalise their knowledge to make new words or to manipulate information towards a self-extending system. Phonemic awareness is an area these students show a weakness in.

Different attempts at writing the same word within the piece of writing occurred with three of these lower achieving students. Each time the word was written, an attempt was made without recourse to past attempts. Anthony wrote vrey/very, 
verry/very, flat/felt, faut/felt, falt/felt, whent/went and wnet/went. When I talked with Anthony about the various spelling attempts for went his frustration with his learning process was evident. He explained "I had it in my spelling (to learn). I practise them all the time and I spell it." Perhaps his frustration with his learning has lead Anthony to his belief that he is not a good speller or writer. His comments indicated that he believed he should be able to commit the word to memory and visually recall it accurately when he needed to. However this visual method of learning these phonetically spelt words has not worked for him. Samantha showed similar frustrations with her attempts. In her use of wse/was and wose/was she explained, "I didn't mean to do that. Sometimes I do an extra letter. I knew it in year 2. I keep trying." Reason et al., (1994) discussed how disappointing it is for all, when students still cannot remember correct spellings in their continuous writing despite conscious effort to learn the words on their list.

There was evidence that inability to pronounce words correctly, or hear the correct sounds, hindered these students' ability to make use of phonographic knowledge. An example was in Anthony's attempts. His story was about his experience at the swimming pool on the water slide (locally named the zoom tube). He wrote tube three different ways in his story: toub/tube, tould/tube and coode/tube. When his spelling of this word was discussed in the interview, he noted that toub/tube was a closer spelling "because tube doesn't start with a c, it starts with a t." I asked how he knew this and he replied, "When I go to the pools I see the word." This evidence indicates that on discussion Anthony's understanding reached closer towards knowing the correct spelling. However he was still drawing on visual recall and, given his difficulty with articulating the word clearly, he had found it difficult to use phonographic information. Anthony also made three attempts at felt: flat/felt, 
faut/felt, and falt/felt, stating that the strategy he had used was 'sounding out'. I asked, "What did you hear?" He replied, "/fa-out/." When I probed him with, "Did it look right?" he replied, "No." However he was stuck on his one strategy of 'sounding out', which had resulted in three different attempts.

Another example of speech affecting spelling was Joshua's attempts of froowing/throwing and fanut/thought. The use of $f$ for the sound /th/ suggests he was not pronouncing the correct sound. Joshua had shown he could visually recall and write the, that, then and them correctly in his story. However, he did not show knowledge of how to represent the /th/ sound for words beginning with $\mathbf{t} \mathbf{h}$ that he had not committed to visual memory. As his speech was inaccurate, he was not able to hear the appropriate sounds and make a match to a known diagraph such as /th/. Another interesting example of incorrect speech causing confusions and contributing to errors was when Matthew wrote whse/was in his story. This attempt prompted a discussion during the interview resulting in Joshua reading this part of his story to me. When he read, "it was still there" he said /wis/. Through discussion it became evident that he clearly believed that wis is not the same word as was and that he had written it as it sounded to him. Concerns about speech difficulties were raised by Brown and McLean (2010) who are local speech therapists working for the schools. They state that children with speech difficulties are at a high risk of literacy failure. Lack of clarity of speech is an area that affects some of these students' spelling accuracy.

\section{Morphological strategies used}

Use of morphology was not common practise for these students. The data for the lower achieving group produced just a few examples of use of morphology combined with visual strategies such as adding $\mathbf{i} \mathbf{n} \mathbf{g}$ to create playing and getting. 
One student could write haven't and didn't and explained that /int/ was written as $\mathbf{n}$,

t.

\section{Risk taking}

Interviews with the students in the less able group revealed reluctance by some to take risks in spelling some words they found difficult. At times students chose to write an easier word rather than attempt a more complex word. During the interview, William showed his reluctance to take risks and his preference for using a safe repertoire of words. In his enthusiastic pre-writing discussion he had used the word jumped. Then in his writing sample he replaced jumped with an easier word, got. His explanation for this was, "There's too many letters in jumped." A further example is when Samantha noted that she had used this practice of choosing an easier word saying, "I didn't know a word so I put another word (not as interesting) in it”. Writing fewer words and using a safe store of words leads to repeating words they know how to spell and less practice through less opportunities to use strategies, and attempt more difficult words. As a way of reducing spelling errors, less able students such as these participants may limit their writing in quality and quantity, resulting in less practice in the use of more advanced writing skills than that of more able students (Allcock, 2006).

\section{Impact of class spelling programmes on spelling knowledge}

These lower achieving students' comments indicated that learning spelling was often thought of as learning isolated words and the connection was not made to using them in text or towards generalising and using useful analogies. There was little evidence of connections made by students between their class writing lessons and class word study of word patterns and morphological knowledge. The students' main description of how they learned spelling was around their list of words that they took 
home on Mondays to be learned and then tested at school on Fridays. Five of the six Group B students reported practising and being tested at home. One student reported he did not take his words home. Practice at home, was described by the students as either, spelling words out aloud, or writing the words. The involvement and effort of family at home, in learning spelling, was evident through these comments made by these lower achieving spellers/writers:

Elizabeth: 'I just practise. My mum says I have to spell them. I say the letters. Mum says if they are correct. At the end she goes over them again. I guess them again. And then she shows me if I get them all right. Sometimes my nana tests me." Anthony: "I practise them, I write them 100 times. I sound them out. Every night." Matthew: "Look, cover, spell, then give it to your nana or parents, and I get them right 'cause I look at them, cover them, say them, spell them."

Joshua: "I need to write down all my words to get an hour or so on the computer. How much words I get right, I get minutes on the computer."

These comments indicate active participation by parents and grandparents, using various methods. However evidence of these students' word knowledge in writing indicates that the time spent with practice may not be enabling these students to use strategies for spelling the words they need in their writing. It is also frustrating for students in that they feel they have learned the words but still cannot spell them.

When a student explains their thinking about learning, an insight is provided into how effective adult feedback has been to them. When these lower achieving students were asked how they knew if they were improving in their writing (Appendix $\mathrm{J})$, these lower achievers projected a face value perception with comments such as "My teacher tells me (that I am improving.)" Also, "We are seniors and the teacher gives us harder work." Or perception was gained from where the student is placed on 
spelling lists: "I was up to because on my list and now l'm up to interesting." And still in discussing the learning of isolated words: "The hardest word last year was way, this year, (it is) ropes." And, "Now I know more words. Because I have got them in my homework and keep on doing them at school." These comments suggest that a score or place on a spelling list was a measure of success. However there is little evidence that these lower achieving students reflected on any other ways of knowing how and why they might be improving.

\section{Use of class peers to assist with spelling}

Through the interviews it emerged that this group noted the use of peers as a useful tool for assisting with writing an unknown word when they were not able to spell it. Data also emerged through the questions from the NEMP (Crooks, Flockton and White, 2007) study (Appendix K) that supported the notion that students made use of peers. When they were asked during the interview 'what do you usually do when you can't spell a word?', 33\% of these students said they would ask a friend. No students would choose to ask the teacher as one of their first two strategies. This use of peers for assistance appeared to be an incidental outcome of being in proximity to other students during the writing process, or through perceptions of the students of their peer's ability, rather than through deliberate engineering by teachers.

Samantha referred to making use of peers she perceived to be good at spelling. "I might ask ${ }^{* * *}$ who is quite smart, on my table, and I ask the other two boys 'cause they know more words than me." I asked her, "Would they help you?" Her answer was "Yes". Anthony reported, "If they weren't smart I wouldn't ask them, if they were smart I would." I asked him, "How would you know if they were smart or not?" "l'd go and look on the spelling list (a list on the wall showing students' names and their spelling groups). See how high the person is." Matthew was less calculating 
in his decision to make use of class peers. "I ask anyone around, do you know how to spell...."

These comments by the low achieving students indicate that some students use peers whom they believe to be 'smart' and consequently helpful. There was also evidence of using those who were in proximity. These students are obviously open to using class peers. There could be potential for use of peers in the class in 'deliberate acts of teaching' (Ministry of Education, 2003, p. 26) to scaffold students' learning with their "zone of proximal development" (Vygotsky, 1962, In Clay, 1991, p. 65).

\section{Use of computers to assist with spelling}

The use of computers as a tool for writing was discussed in the interviews (See Appendices $\mathrm{J}$ and $\mathrm{K}$ ) to determine whether they are used by students to assist with spelling words. The interviews revealed information about the frequency of access to this tool and knowledge of use of the technology. One of these Group B students reported using a computer for writing at school 'quite a lot' and one reported 'a little' use. However, the other four B Group students reported not using one at school at all. On use of a computer at home for writing, half reported using one 'heaps' with some students discussing laptops as readily accessible. One student used a computer for social networking, and another used one for homework. Three of the six reported no access to a home computer. One of these students, who had no home access, made use of the facility at the local public library, and at a friend's house for playing games. Clearly, equity of access may affect these students' opportunity to use information technology to support their writing and spelling.

This study also gauged the knowledge the students had of the spell-checkers when writing on computers. As some of these students reported little or no access to a computer, it could be assumed they would not know about the computer spell- 
checker tool. However it was interesting to check this out. The students were asked the NEMP (Crooks et al., 2007) question, 'What do you usually do when you can't spell a word in writing?' (See Appendix K) and predictably none of these students chose 'use the computer spell-check' as one of their first two responses. Also predictably, these low achieving students' knowledge about the function and use of spell-checker tool was fragmented, with inaccurate knowledge or no knowledge of the red and green underlines, or methods of correcting identified spelling errors. For example Elizabeth explained, "Red line you got it wrong, green line you got it right." Matthew, who has access to a laptop at home, had some knowledge and a strategy and noted, "I could press back back back back back and try and spell it again, or ask how to spell it, or go on 'Google search' dictionary.”

These students are not making use of a computer for their regular day-to-day writing activity at school, and with their current knowledge would have difficulty with purposeful independent use. To be successful with writing on the computer these lower achieving students would require scaffolding of their learning. Regular use for draft writing could provide them with an opportunity to practise combining their spelling strategies, taking risks and using the spell-checking option to monitor and check their words.

\section{Beliefs on the importance of correct spelling}

It is helpful to gain a perspective of attitudes towards correct spelling by the students as this may provide further information about their spelling behaviour and meta-cognitive thinking.

When the students were asked during the interview if spelling is important (See Appendix J), five out of six students from the B Group said 'yes' and one said 'sometimes'. All but one student gave reasoned answers justifying their choices. 
Answers and explanations indicated that the students believed that there are times and places where correct spelling is a necessary tool. They had a clear understanding of spelling being part of writing and that the process of writing is a skill they will continue to use in life beyond the classroom. Two of the comments reflect these boys' thinking and the connections they have made between now and their adult lives. Anthony noted, "Yes at university. If you own a company you should know how to spell words. If you get it wrong you might get fired." Matthew explained why he thought correct spelling was important saying, "Yes because if you don't get correct spelling nobody will know what you are trying to spell and you won't get a good job. And you won't get any money. Or else you would starve to death. Or you could just fish. I asked him, "What kind of job do you need correct spelling for?" "Probably plumber because you have to write notes and building, because if you are trying to leave a note saying 'don't use the lights' you might spell 'do use the lights' or muck up. They use the lights... zzz, and might get an electric shock." Matthew and Anthony projected their thoughts towards predicting their future needs, the ability to spell well. Joshua thought about the school community and what the implications would be if there were mistakes in the school newsletter. He believed his Mum would say, "'The school is not good so we'll move to another school.' They will think they will teach the children the wrong way."

Samantha and Elizabeth gave answers to suggest that their thinking about correct spelling was centred in their writing at school. Samantha noted the importance: “In publishing 'cause the teacher doesn't like us making mistakes in our books. Because sometimes we read it (our writing) at assembly and we would get a word wrong. Sometimes at home you read it out and you might forget the word." Elizabeth added, "No, because you are just learning how to spell. (In your draft its ok 
not to get everything correct). 'Miss' tells us if we need all our words correct. Sometimes she says if you don't spell it all correct it doesn't care. But sometimes we have to get it correct. (Example): When we are writing a letter, so people can understand it. (Otherwise) They won't be able to understand."

From these comments it can be deduced that these lower achieving students believed in the importance of correct spelling. One reason noted was to allow the audience to gain meaning. They also felt judgements were made about people who do not present correct spelling when they are writing for an audience. These are interesting reflections from a group of struggling spellers some of whom believe that they are not good spellers themselves. The tension between values and reality may cause frustration for these students.

\section{Summary of strategies used by students achieving below expected level}

This summary answers research question 1. The students who were assessed by their school as writing and spelling below expected level, and placed in the B Group for the purposes of this study, wrote their writing sample (See Appendix N) using their own store of visually recalled correctly spelt words, along with words they attempted to spell. Correctly spelt words were mainly one-syllable essential list words. However many one-syllable consonant-vowel-consonant words were not spelt correctly. Very few multi-syllabic words were correctly spelt. Where words were attempted but were not written correctly, students reported using phonographic strategies and often called this 'sounding out', or they reported that they 'guessed'. There was some combination of visual and phonographic strategies used, however combining of strategies appeared to be uncommon and employed randomly. For some students, incorrect speech affected the way words were spelt. These lower achieving students did not report making use of class word study to assist them with 
their spelling problem-solving. Lists of words were practised at home and in five out of six students, they reported that regular support for learning words was provided at home. Frustration was noted among these lower achieving students over their difficulty with accurate visual recall of the practised words when they needed them in their writing. Their frustration was reflected in the self-assessment of their ability in spelling and writing, four out of six not being positive about their writing and spelling ability. The amount of words written in the writing sample was minimal and words were of a limited range specific to the individual. Reliance on a small range of words well known to the student, writing a smaller volume of total words at a writing session, and reluctance to take risks with consequent substituting of an easier word, all contribute to less opportunity for these lower achieving students to practise spelling in writing. Writing less variety of vocabulary also in turn results in less practice using more advanced writing skills than more able students (Allcock, 2006).

These students reported generally not using a computer at school for writing. Half reported some computer use at home, using it for social networking and homework. Therefore use of computers for processing writing, proof reading and practicing spelling strategies has not been part of the options these students have had ready access to learn with.

These below average writers appeared not to be making the links between their "items of knowledge" Clay (1991, p. 328). Nor were they combining strategies that would assist in self-improvement. Clay states that although we each strategise differently from each other, there being no one right way, some strategies are more useful than others at any one time to problem solve. These lower achieving students display a weak base with inefficient use of strategies (Clay, 1991). Phenix et al. (1991) believe that a good speller is not a person who is able to memorise the most 
words, but a person who is able to "figure out the logic of words" (p. 18). These below average writers and spellers have figured out some of the logic. However, use of meta-cognitive awareness to apply their knowledge and strategies to construct new words does not appear to be part of their regular problem-solving repertoire, and not yet embedded in their writing behaviours. Explicit links need to be made for these students in the context of their own writing. The "deliberate acts of teaching" (Ministry of Education, 2003, p. 78) need to include feedback on their spelling attempts and links to prior learning. Croft (1998) believes it is essential that spelling knowledge is transferred. He notes that use of spelling needs to be regarded as a skill of writing and taught within the structure of the classroom writing programme.

These students know spelling is hard for them and this affects their belief about their ability. One student summed up his feelings and need for scaffolding by stating, "Some words are just too hard for me, just help." The challenge for educators is defining what 'help' is, and how can 'help' be provided for students to enable them to access useful strategies, and apply knowledge and strategies to problem-solve and construct new words. Students having difficulty with spelling need to be taught to use meta-cognition awareness in a problem-solving process of "figuring out the logic of words" (Phenix et al., (1991, p. 18).

\section{Strategies used by Year 4 students who are achieving at expected level}

\section{Introduction to the A Group}

These participating students were assessed by their schools as achieving within the expected range of Level 2 in the New Zealand Curriculum (Ministry of Education, 2007) for spelling and writing achievement. These students believed they 
were very good or quite good at spelling and writing. When they wrote their sample (Appendix N), they showed substantial planning of their writing using numbered and ordered ideas, including written vocabulary within the plans. The pre-writing planning supported the story towards production of length and sophistication of ideas. The length of the writing sample and the variety of vocabulary used, afforded opportunities to try new spellings. Written vocabulary in the stories included a combination of high frequency and high interest vocabulary. The total different words written correctly in their writing samples ranged from 33 to 146 words. The total running words written (correct and attempted) in the writing samples ranged from 114 to 497 words. These totals contrast markedly with those of the B Group.

\section{Visual strategies used}

Words written correctly by these students in their writing sample, included a number of words listed as the most frequently used words in the essential lists (Croft and et al., 1998), but also a number of more complex words, many of which were personal to the student. The students reported that some of the visually recalled words were ones that they had used themselves lots of times, or frequently seen written. Some high interest words were remembered from books. Examples were Daniel seeing stomach in a book and Madison remembering boat from a poem. Two students made close attempts at hospital and cited familiarity with the place and seeing the word as factors contributing to their visual recall. There were also a variety of people's names written correctly that were personal to particular students. The words had obvious importance and frequency of use.

\section{Phonographic strategies used}

The students noted that when attempting words they 'sounded them out'. With this group, 'sounding out' often included the use of syllabification. When Daniel wrote 
exibition/exhibition, he explained, "I sounded it out. I went ex/i/bi/shin." He called this method, "breaking up the letters." These A Group students also used terminology such as "breaking up words", "splitting apart" and "putting groups of letters together". Examples of words they split phonologically to assist with the written form were /scr/ and /een/, /for/ and /ever/, and /pic/ and /ture/.

Analogies between words with similar orthographic patterns were often used to generate others. Some of these analogies showed use of quite complex strategy use. For example Daniel saw analogies between the words every and forever, and shade and shape. Madison could change crash to crack. These examples show a combination of visual and phonographic strategies through use of meta-cognition. Ethan's explanation of how he employed a combination of visual and phonographic strategies to problem solve, showed his meta-cognitive thinking: "If you know another word that is pretty much like it you might get it right because you sound it and get the ending bits and the front bits. If you know a word that sounds like it and you think this is the same letters in the front and you might get it right."

Many word attempts of these A Group students were phonetically accurate, reflecting the successful use of sound analysis. Words attempted by these students were often close to the correct spelling. Their use of monitoring was shown through their awareness that the attempted words were not correctly spelt.

Through examining spelling attempts of student's words, a judgment can be made as to whether the student has the necessary phonemic awareness and spelling pattern skills (Allcock, 2006). Examples of phonetically accurate attempts were pleas/please, becaus/because spoted/spotted, awnser/answer, dokter/doctor, exibition/exhibition, extremly/extremely, stoped/stopped, windid/winded, tacken/taken, raceing/racing, alean/alien, stoped/stopped, lisined/listened, 
rist/wrist, togeather/together and finaly/finally. When attempts were not correct, it may be that the selection of graphemes to represent the phoneme was not the right choice (Brann, 2004). This is an area for deliberate teaching. Examples of phonetically inaccurate spelling by one student were shown in exied/excited and moths/months where she clearly was not using enough phonemic knowledge. This is what she needs to learn.

When questioned on their phonological knowledge of words, most A Group students were able to give the beginning, middle and end letter of a consonant-vowelconsonant (cvc) word (tending to give the letter, not the sound) and also the number of syllables in a word. There was a mixed response in the understanding of the number of individual sounds (phonemes) in a word. Ethan was the only student out of the 12 participants who could consistently give the beginning, middle and end sounds (he gave the letters) of given words, the correct number of sounds (phonemes) in given words, and the correct number syllables in given words.

\section{Morphological strategies used}

Morphology develops later in a student's spelling development. Some errors point to the student not yet possessing the supporting morphological knowledge needed for the word (Brann, 2004). When students used a visual or phonographic strategy and combined with a morphological strategy through the process of metacognition, they showed a stronger "network of strategies" (Clay 1991, pp. 326-327). These A Group students were able to explain use of morphological knowledge. Examples were use of apostrophes, compound words and tense. Words that end with i $\mathbf{n ~ g}$, as in sitting and smiling, and compound words such as boyfriend and forever were used accurately. Chloe wrote swimming and gave a detailed expanation of her morphological strategy saying, "If you want going, doing, 
throwing, if you want /ing/ on the end you put i n g; e d is for a word that's past and the $\boldsymbol{i} \boldsymbol{n} \mathbf{g}$ is going to happen." I asked her, "What about $\mathbf{s}$ ?" "It's right now." This comment demonstrates Chloe's ability to apply her learning to new needs. She can "figure out the logic of words" around tense and as a consequence can use her knowledge to "construct them as needed" (Phenix et al., 1991, p. 18).

Similarly, Emily was able to discuss her knowledge of contractions to transfer to new spellings required. She discussed her knowledge saying, “Didn't has an apostrophe, it's a shorter word." She continued to demonstrate her use of metacognition to apply her learning to new contexts, giving another example: "Let us. You can cut it down shorter to let's." Emily also spoke of a useful mnemonic to remember the spelling of people. (People eat oranges people like eggs), taught to her by a teacher. She noted use of rules such as change the $\mathbf{y}$ to $\mathbf{i}$ and add $\mathbf{e} \mathbf{d}$. The variety of strategies that Emily described suggests that she can select appropriately from a personal "network of strategies" (Clay 1991, pp. 326-327).

Being automatic with processing is essential to good strategy use, and these students who were achieving at expected level, showed more automaticity with the application of a useful strategy and were able to explain what they did and why. Olivia was able to make decisions to use a single strategy or combine strategies. She described her spelling behaviour which depended on what was required, saying "Sometimes I look in the dictionary, sometimes I sound it out, sometimes I guess." When Ethan described his spelling behaviour, there was an indication of automatic processing of his strategy combinations. He said, "Sounding out, guessing, and what you know, and mixing these together." Ethan's description of his process of combining strategies to spell new words as "mixing them together" is an example of Clay's (1991) description of building of an "inner control” (p. 327). 


\section{Risk taking}

One of the A Group students showed some difficulty with taking risks when attempting words she was unsure of. Chloe discussed her difficulty with the word grandma. She noted, "I would actually write nana not grandma because it would be easier." She also commented on another occasion when she wanted to write silver but wrote grey because she knew how to spell it. However, she was also able to give an example when substitution didn't work: “I was writing and didn't know the word, so I wrote another word and it didn't make sense with the sentence." This comment indicates that although she practised substitution of words, she realised its limitations, and knows that risk taking is an area of new learning of her. This is where there is a need for "cognitive emphasis" for her (Ysseldyke et al., 2002, p. 5). Illustrated previously in this chapter was her clear understanding of the use of tense. Through examination of writing and discussion with students about their writing, the area of "instructional match" (Ysseldyke et al., 2002, p. 5) and "cognitive emphasis" (Ysseldyke et al., 2002, p. 5) can be revealed. Chloe will need scaffolding to assist her with this self-identified "zone of proximal development" (Vygotsky, 1962, In Clay, 1991, p. 65).

Olivia had a comment that could assist with scaffolding Chloe's learning. "We should try and spell it before we actually know how to spell it. Even if you don't know it you can try because you will get some of it, you will know the bit you need to be able to learn." Olivia's comment illustrates her use of meta-cognition and her active theorising about the organisation of written language, and how she uses risk taking in a positive way to take charge of her learning. Being able to think and articulate what they know and can do helps students to problem-solve new challenges (Ministry of Education, 2003). 
Risk taking needs to be used in conjunction with approximating and tempered with the expectation that known words are spelt correctly. If students write a word incorrectly too often, the incorrect spelling is reinforced into sight memory (Allcock, 2006). Ethan uttered his cautionary message about spelling a word incorrectly too often, with the same thoughts as Allcock (2006): "If I write it lots of times and get it wrong I'll probably get it wrong until I remember it, until we learn it again. (Then) I'll probably remember it and write it correct." Ethan's comments demonstrated his ability through meta-cognitive awareness to self-monitor his learning, think about his learning processes, and talk about his own learning.

\section{Impact of class spelling programmes on spelling knowledge}

These A Group students demonstrated transference of classroom word study into their writing process. Their use of morphologic and phonographic strategies could be linked to direct teaching of word study at school. Some students were able to express what classroom experiences had contributed to knowledge and strategies. For example, Olivia discussed finding dictionary meanings, writing sentences, handwriting, story writing and testing each other on spelling words all contributed to her success as a speller. She spoke of her enjoyment of literacy challenges such as when she had to use all of a group of topic words in one sentence. She recalled in the interview, that in class she wrote: "In the solar system we have eight planets orbiting the sun, our huge star." Ethan was able to describe what happened for him when time is given for learning to be embedded. He talked about how learning needs to be reinforced and links made, so that it can be applied to writing: "If we are learning one thing and tomorrow we do something quite like it, it helps me to spell some words that I don't know (in writing). There is a clear distinction here between the lower achieving and average-achieving students in their ability to transfer class word study to its 
application in continuous writing. This more able group demonstrated that they made the connections.

These A Group students were also given word lists to learn for homework. Two of these six students reported practising the words at home. Five of the six reported having the words tested at home. One student didn't comment on what she did with the words at home. One student's family also conducted word quizzes at home for extra practise.

When a student explains their thinking about learning, it gives an insight into how effective feedback has been to them. When asked how they knew if they were improving in their writing, these average achievers had plenty to say about selfimprovement with comments that suggest a deeper self-reflection than their B Group peers. One student reported, "Last year I used to just leave it and not go back to it, and just let the teacher do all the work. This year I have been trying not to let the teacher do it and just try to do it myself." This student demonstrated taking notice of feedback: "Last year on my report she (teacher) gave me a bad report and this year she writes it's pretty good and last year it wasn't that good, so I am probably improving in my writing." The next student's comments result from reflection of their quality of written output: "Cause last year I used to only write two sentences or three." Another said, "Last year I never knew this word, and this year l've never known it and I (now) just know it." This last comment suggests the evidence of improvement for this student was at face level like that of the B Group: "Because we are in a higher class."

\section{Use of class peers to assist with spelling}

This group also noted the use of peers to assist with writing an unknown word. When asked the NEMP (Crooks et al., 2007) question (Appendix K) 'What do you usually do when you can't spell a word?, 33\% of these students also said they would 
ask a friend. The NEMP (Crooks et al., 2007) nation-wide results were that $12 \%$ of Year 4 students would ask a friend. None of these A Group students would choose to ask the teacher as one of their first two strategies, compared with the NEMP (Crooks et al., 2007) nation-wide results, where $17 \%$ of Year 4 students would ask a teacher. Comments from these A Group students suggested they were usually discerning about which peers in the class they asked and showed less reliance on other class members than the B Group. The two comments that were made about peer use were: "I ask my friend, I call her 'Dictionary'. She is quite useful. She doesn't mind. If she is not there I would sound it out or check with the teacher."

"Asking someone next to you (might not work), because they might not know how to spell it. And then you get it wrong." These comments indicate less of a need to check spelling with class peers. This group of students did not give any comments to suggest other students in the class relied on them to assist. However their comments show they have much knowledge and strategies that could be used to scaffold their less able peers.

\section{Use of computers to assist with spelling}

Use of computers as a tool for writing was discussed in the interviews with these average achievers (See Appendices $\mathrm{J}$ and $\mathrm{K}$ ) to determine if computers were used as a tool to assist with draft writing and the consequent spelling words. The interviews revealed information about the frequency of access to computers and what impact their use is having on learning. On the use of computers at school, one of these A Group students reported not using a computer at school at all, and the other five reported 'a little' use. On use of the computer at home, one student reported using one 'heaps' and five said 'a little' use. Students reported the computer use at school was in publishing writing that they had drafted in their writing books. 
The knowledge the students had of the spell-checker tool varied. The students were asked the NEMP (Crooks et al., 2007) question, 'What do you usually do when you can't spell a word in writing?' (See Appendix K), and as with the B Group, none of these A Group students chose 'use the computer spell-check' as one of their first two responses. When I asked if they have seen or used a computer spell-checker, two out of the six in this Group A, said 'yes'. However most had seen the underlines within the text. Ethan discussed his experiences and knowledge saying, "Once it underlined it green, it didn't make sense for the computer. If it's red underneath, it's spelt wrong. (When it is spelt wrong, I/we) pretty much delete all of it and write it and make it correct, but if it went green underneath, we would go to the end of where it is and press 'space' or 'enter', or click and the green lines would go away. If they stayed there, you click again and change the word to a better sentence." Ethan revealed that he possessed some useful information but to make full use of the knowledge in writing on a computer, he would need some scaffolding to extend skills to a more useful level. Olivia had some confusing knowledge. "Red line means your words are too close together. Green one means you've got the name correct if you write a name. You can back space it and fix it up." Other students talked of other methods of problem solving if a red under-line was shown in computer writing. Students would search for the unknown word in a book dictionary, ask the teacher, or syllabify the word by the technique of clapping the syllables while saying the word. Daniel showed a clear knowledge of the use of the spell-checker as a useful tool in writing. His knowledge of the use of the spell-checker was attained through incidental peer interaction at school, which provided the scaffolding he needed. Of the 12 students in the main study he was the only one who gave a clear explanation that indicated he could use the tool. (The red under-line means), "It's got a few mistakes in there. I 
think you click it and you come up with this thing and you right click it and it comes up with this thing and you click the right word. You have to right click it, the right side, not the left side." I asked him, "Who taught you?" His answer was, "A big kid (in) Year five or six." This is an instance where a student peer successfully scaffolded Daniel's learning. This very important learning appeared to have taken place through incidental peer interaction. More use could be made of peers to scaffold other students in the learning. Comments from these students suggest that they are not making use of a computer for their regular day-to-day writing activity. These A Group students that are writing at expected level, have more knowledge of computer use than the B Group students and probably would be able to successfully write drafts on the computer and use spell-checks if given a small amount of scaffolding. Regular use would provide opportunity to extend their spelling strategy use and use the spellchecking option for monitoring and checking.

\section{Beliefs on the importance of correct spelling}

As with the B Group, the average achieving writers were also asked in the interviews about their attitudes about the importance of correct spelling. An insight was gained on beliefs about where they believe correct spelling fits into the writing process. When the students were asked during the interview if spelling is important, one third of Group A students said 'yes' spelling is important, and two thirds said 'sometimes'. These answers reflect the students' meta-cognitive awareness in that they think of writing as being a skill for life beyond the classroom. They believe that there are times and places where correct spelling is necessary.

When discussing correct spelling, these A Group students thought about the different contexts of draft and published work and why work published for an audience needed to be correct. There was a firm belief with these A Group students 
that published work needs to be correctly spelt. Emily noted, "If it was in my writing book, that's just our starting work.... and so if you have any spelling mistakes it'll be in the writing but not on the good piece of paper" (published). "(If there were mistakes in the published work), they (the audience/reader) might try and work it out for minutes and minutes and they might get bored of reading it and then they'd move onto another one and you want them to read all the story." Madison reported, "Because they might go 'what's this word?' They won't know what the word is if it's wrong, and you (audience/reader) have to start again." Ethan said, "That's why it takes ages and ages to make a story. In your draft, yes (errors are ok) but when you are doing your real writing you want to try and fix it in your draft. And put the right word in you draft onto your good publishing paper. So that's what we do in our class." Olivia noted, “Sometimes it is (important), because some people mightn't know what it means. Like our Mum and Dads, and our families. In assembly, because we might get a word wrong and we might say something else. (The school newsletter should be spelt correctly) because they (parents) might think their children will spell like that." Chloe stated, "Sometimes, when you are writing a letter, a book, or a story. Because if you write a story for other kids to read, you have to get the correct spelling. If you don't get it all correct, you can fix it up and write another one. Sometimes they can't understand it and they can go show the teacher and she might not understand it either. It's not so important when you are only just little and you just write a story for school and if you make mistakes you can cross it out and keep on going. I just keep on learning."

As with the B Group boys, it was a boy in the A Group who projected his thoughts about the use of spelling towards his future use of spelling as an adult. Daniel commented, "Yes, when writing a story, and going on a job, when bosses have 
to write a letter, so people can read the words. In case the bosses have to write a letter to their workers. If you write a story and you are an author. So people can read the words. They wouldn't finish the book off with even more spelling mistakes."

These students were able to view writing as a process, where use of correct spelling became more important as the writing became closer to the finished product that an audience would be reading, as this is the time when the audience needs to be able to gain meaning from the writing.

\section{Summary of strategies used by those achieving at expected level}

In summary, and in answer to research question 2, these students, who were writing and spelling at an expected level for their years at school, showed a growing confidence in their use of spelling strategies. Discussion of words used in the writing sample demonstrated use of a variety of visual, phonographic and morphological strategies to spell words, and also a combination of these. They could explain their meta-cognitive awareness that lead them to particular strategies and how they varied strategies according to the need. Meta-cognitive awareness was illustrated in comment such Ethan's and Olivia's, indicating that these students strategised independently to problem-solve challenging words.

The words they used in their writing sample included a combination of high frequency and high interest vocabulary. These students showed less reluctance to take risks and were generally confident to use their strategies to approximate when they needed to write new words. One student identified that reluctance to take a risk with new words has negatively affected her writing quality.

The total different words written correctly in these students' writing samples, was greater than the amount of different words the lower achievers wrote. The total running words written (correct and attempted also contrasted markedly with that of 
the B Group. When these students write more at each writing session, they have opportunity to practise more words. Also, use of a greater vocabulary in turn contributed to more advanced writing skills (Allcock, 2006).

The average-achieving students generally reported that they used a computer for writing at school 'a little'. Computer use at home was generally also noted as 'a little' use with one student using a computer a lot at home. Use at school was reported to be for publishing their writing. As with the B Group, use of computers for processing their writing, practicing spelling strategies and proof reading has not been part of the options they have had ready access to learn with. One student had a working knowledge of the spell-checker tool, taught to him by a peer.

\section{Summary and comparisons of the two groups of students}

In answer to research question 3, the average achieving writers displayed a much stronger base of efficient use of strategies than their lower achieving peers. They made links with prior learning, using the knowledge they had and combining strategies to proble-solve. This meta-cognitive problem-solving approach, appears to lead to continuing self-improvement. Applying their knowledge and strategies to construct new words was becoming embedded in their writing behaviours. These average achieving students have in many instances "figured out the logic of words", the requirements for a good speller (Phenix et al., 1991, p. 18). They displayed a stronger base from which to work, and were already independently making useful choices about strategies and combinations. They were indeed using more sophisticated strategies. This compares favourably with Brann and Hattie's (1995) findings.

The lower achieving writers tended to see each new word as just that: a new word. They did not make links with prior learning. Their "items of knowledge" Clay 
(1991) were not transferred to problem-solve new words. These students generally recalled known words visually or applied phonographic strategies to their attempts, calling their actions 'sounding out' the words. There is a need for more use of metacognitive awareness in viewing spelling as a series of problems that can be solved with strategies (Phenix et al., 1991) and combinations of strategies. In order to come closer to an "instructional match" (Ysseldyke et al., 2002, p. 5) for the lower achieving students they will need to be scaffolded towards making links with prior knowledge, manipulating their knowledge and combing strategies as their more able counterparts are using.

The main learning opportunities discussed by the participating students can be categorised into three contexts: Class word study, learning words on their personal lists, and the classroom writing lessons. The average achievers made use of all these learning opportunities in the class programmes. They made connections between their learning in class words study and their lists of words to their needs in writing. However, the lower achievers showed little evidence of making the connections between these three learning contexts. For these students the links need to be made explicit through "deliberate acts of teaching" (Ministry of Education, 2003, p. 78).

When the lower achieving students can explain their thinking the way Ethan, Olivia and Daniel do, we will know that they are making use of the class programmes to improve their spelling. Through examining students spelling attempts in their writing, knowledge will be gained about the learning needs of individuals. In order to get a closer instructional match these students need links made explicit. There are two key areas for which linking is crucial: The connections between the three main learning contexts; and the links between prior knowledge about words and new problem-solving through combining strategies. 
Some methods of ensuring this could be in the use of feedback specifically about their spelling attempts in their writing. Also, selection of spelling words and specific word study focussed on their current identified spelling need with the expectation that the small steps of new learning are transferred to their writing. As words are more frequently written, they will be able to be more easily accessed visually. Quicker visual access, along with more use of automatically combining strategies, may lead to more words written in classroom writing lessons, with the consequent practice of words and more sophisticated writing. 


\section{CHAPTER 5}

\section{Results and Discussions - The teachers' views}

This chapter presents and discusses the results gained from the contributions of teacher participants. It also includes some discussion of the students' views and some comparisons between teachers and students' comments. It seeks to answer the research question 4, by asking teachers what strategies and knowledge they believe are important in teaching students to spell words in writing and by comparing the teachers' beliefs with strategies the students use. The questions were addressed through teacher interviews and interview questionnaires. (See Appendices $L$ and $M$ : Interview Schedules for Teachers). Nine teachers were interviewed, three from each of the three participating schools. Three teachers, one teacher from each school, were the current teachers of participating students. The other six teachers were teachers of junior students, two teachers from each of the three schools.

\section{Pedagogy}

The New Zealand Curriculum states, "Effective pedagogy requires that teachers inquire into the impact of their teaching on their students" (Ministry of Education, 2007, p. 35). Participating teachers made use of self-reflection and evidence from learning and teaching in forming teacher beliefs. The teachers believed in the importance of identification of learning needs and teaching at instructional match.

The participating teachers added to their knowledge and beliefs about teaching spelling from a variety of professional sources. Much knowledge has been gained from large amounts of professional development around literacy teaching and learning. For example the Ministry of Education initiated Cluster Schools' 
Improvement Projects have been part of the professional development accessed by all the participating schools (Ministry of Education, 2010c).

\section{Teachers' beliefs about how students learn to spell}

The teachers cited use of visual memory and letter sound knowledge being the main strategies used by students to spell words. Most teachers believed that students have a main tendency towards being able to learn more easily either visually or using letter and sound knowledge. One teacher described students' leaning towards a particular strategy in this way. "Some (students) will be weighted more heavily one way because that's what we are like as learners." Another teacher noted, "It's finding the different ways all people have got. I think children have their ways of learning fastest. Depending on what they notice."

\section{Teachers' views about teaching spelling in classroom programmes}

The teachers were positive in their approach to providing for the diverse range within their classes and for providing time for spelling to be taught. They felt that it was important to not let the busy classroom timetable be a barrier to timetabling spelling teaching into the school day. The data from teachers and the students revealed three main learning opportunities that are provided for students on a regular basis in classrooms. They were daily writing, study of words and their make-up, and learning of words from allocated lists. Each of the three areas was timetabled into the class programmes.

\section{Word study}

Teachers believed that the class teaching of spelling skills through word study was a very important component of literacy teaching. This spelling instruction, was referred to by teachers as "deliberate acts of teaching" (Ministry of Education, 2003, p. 78). This direct teaching about the make-up of words was accompanied by follow- 
up independent work for students to practise their new learning. Study involved use of essential list words (Croft et al, 1998) and programmes such as "Switch on to Spelling" (Allcock, (2006).

In the student interviews, the A Group students spoke of accessing information from this direct teaching to build on the strategies they used when independently spelling words in their writing. The B Group students made very little reference to the transferring of word study learning into their classroom writing. The B Group showed little use of making their own connections independently, between classroom word study and the spelling they used in their daily classroom writing. It appears that the lower achieving students required more scaffolding to make the connections between the learning opportunities. One of the teacher participants refered to unconnected items of knowledge as "fragments." She explained, "Without those fragments tying up together, you've got loops. You've got learning knowledge missing."

\section{Daily writing}

Classroom writing lessons were a regular part of the programme. Teachers generally believed that when students are writing a draft, they should spell correctly the words they already know. Also students should be encouraged to take risks and make use of approximating to try to spell unknown words. However there were some variations within the general beliefs.

Teachers of Years 1-3 (junior) students

One of the teachers of the junior students pointed out that approximating took precedence over correctness when new entrant students are writing, as they are new at learning to write words. Another teacher believed in emphasising correct spelling of the basic words as soon as words were introduced to the class and available as a model to copy. 
Another teacher of juniors made an important point about being clear about the learning focus and being explicit to students about this. She explained that when students are creating ideas with new vocabulary, correcting spelling in a piece of writing could be a later focus in the class writing lesson. "The learning intention for the day is a factor. So if it's a task where I want them to write as many ideas about something and not to get hung up about the spelling, then that would be a time when spelling is not particularly important. Some kids can get a hang up and the flow of writing stops because they are so worried about getting the word spelt absolutely correctly. So there will be some times when I say, 'I am not looking at spelling today. That is not what we are learning about." "This teacher's comments suggest that she was encouraging improvement in the complexity of the writing through encouraging risk taking. Students need the freedom to take risks to try out spelling strategies and use new vocabulary (Gentry, 1987; Graham et al., 2006).

The teachers of the junior students reported that feedback about spelling was given to students during classroom writing lessons and when students had completed the draft. The teachers encouraged students to approximate words by listening to the sounds within a word and recording the corresponding letters. Some teachers used sound boxes to assist students to hear the phonemes, for example "Elkonen" boxes (Allcock, 2006, p. 35). Sound boxes are a technique used by Reading Recovery teachers, and some classroom teachers have adopted the technique for use in classrooms to assist with hearing and recording sounds (Clay, 1993).

Teachers of the Year 4 students

Teachers of the participating Year 4 students reported that there was an expectation that Year 4 students would independently monitoring and checking of their own writing. Students were expected to underline words they had attempted, 
and correct them when they were able. Teachers would direct to appropriate resources to locate correct spelling for the identified word attempts. Examples of frequently used resources noted by teachers were dictionaries, the essential lists (Croft et al., 1998), and classroom resources such as topic word charts and alphabetical word cards. Using the essential lists for this purpose is a helpful way of exposing students to the correct models and core vocabulary (Croft, 1998).

The teachers of the Year 4 students offered varied perspectives on how much emphasis should be put on correct spelling in draft writing and the use of approximating.

The first teacher believed that when students realised that they needed to get the message across to an audience, their spelling improved. This teacher stated that it was better for a student to take risks in spelling, in a supportive environment, than be a non risk-taker and consequently write very little. She commented, "It's very hard to help somebody to achieve if they won't take any risks and won't get anything wrong." Through her comments, this teacher indicated that she could work on identified needs and give feedback through analysing spelling attempts.

The second teacher spoke of the importance of correct spelling when the writing is produced for others to read, and also noted that judgements are made about people based on their spelling. She also felt that correct spelling should not be an emphasis in the students' first drafts. "Not in the first draft. It certainly has a high focus at the end when they have finished all their writing and they are happy with what it sounds like and they are happy with the flow of it, and what it says, then we go back, and they do the first check, and they go 'I know this word isn't right. I can tell by looking at it.' They will underline it. I usually choose one or two words that they have underlined, and I will give them prompts as to how they can find it." This teacher 
noted that the locating of the correct spelling needed to be scaffolded for the student, by assisting with decisions about which words to check, and where to locate the correct model. She had a cautioning comment about the over-use of the dictionary, pointing out that its use requires teacher scaffolding. "I think it gets drummed into kids 'go and look in the dictionary'. But it's not always the best way. They come across a whole lot of words that look very similar. And they end up writing strange things." .

Her comments also stressed the importance of attending to and giving feedback to the content and meaning of the writing in the first instance. If spelling is the first point attended to by the teacher, or there is a heavy emphasis of spelling being correct in the draft, it may take the focus away from the message.

The third teacher voiced her concern about some students continuing in the approximating stage for longer that it is appropriate in writing development. She also indicated concerns about students who are not spelling basic essential list words (Croft et al., 1998) correctly in their draft stages of writing. She stated, "When they write a word and just guess it, approximation, some children never ever move on from that. I've got children in my class that still approximate all the words. They might have essential list 1 (Croft et al., 1998) words, but the rest of them are just a guess. How can someone read their writing if it's all guessed?"

Hood (2000) points out that invented or approximated spelling should be viewed as part of a developmental process and that by age nine or ten a student should not need to 'invent' spelling. This teacher assisted lower achieving students to immediately locate essential words by having an appropriate list of words they were likely to need attached to the inside of their draft writing book. 


\section{Spelling Lists}

All teachers reported that part of the spelling programme involved students having personal spelling lists. This component of the spelling programme involved each student having lists of words to learn. Students took the lists of words home on a Monday as part of the homework programme. The expectation was that they were to be learned and tested at home and on Fridays the words were tested at school. One of the main resources from which words were selected, was the group of essential list words (Croft et al., 1998).

All the teachers' of junior classes reported that their students' words were sourced from the essential lists, or adapted lists. Some schools have adapted the way the lists are presented to the students, taking into account relevance of words to the students. In one school spelling and reading sight word were linked.

The three teachers of the Year 4 participants had varied approaches for the home lists, with each class selecting words differently. One class selected from the essential lists and commonly miss-spelt words (Croft et al., 1998), followed by other more advanced lists of words. A class in another school used words that had common patterns and analogies as a basis for homework lists. This could be useful if links are made to problem-solving words required for the students' writing. The class in the third school selected words that were of topical interest to the class to enable familiarity of vocabulary.

It was felt by some teachers of juniors that through selecting words from the essential lists (Croft et al., 1998), words might not be matched to students' ability to learn. Also pointed out by these teachers was that words selected from essential lists are often a group of unrelated words, and not specific to immediate need in writing. The result could be that the words that are not used in writing would be forgotten. As 
Reason et al. (1994) point out, rote learning of a word is only useful if the words are used frequently enough to pass into long-term memory.

The Literacy Learning Progressions notes that after three years at school students should be "using their visual memory to spell personal vocabulary and highfrequency words" (Ministry of Education, 2010a, p.14). Direction in this document points to a requirement for mastery of essential lists $1-4$ and some words from lists 5 and 6, (Croft et al, 1998) by the end of the students' third year. This direction may have resulted in teachers selecting word from the essential lists in preference to a student's individual vocabulary and spelling needs. Croft (1998) did not intend that the essential lists would be used in this way in the junior classes. Croft believes that spelling needs to be regarded as a tool of writing and taught within the structure of the classroom writing programme. Although Hood (2000) advocates the use of a spelling homework learning system, he also suggests that the first place for accessing words to learn should be from students' own writing.

While words need to be memorised so that students have knowledge from which to base their strategies, there is a word of caution from Phenix et al., (1991) who point out that students may think that memorisation is the only method of learning to spell if there is not opportunity to make links with known words.

The learning of the lists of words was closely linked to homework. Some teachers were concerned about spelling being part of homework. Concerns were raised about the time used to organise lists, along with the subsequent individual testing of each child. Another concern raised was the use of parents for teaching spelling at home. One teacher felt that sometimes spelling is treated like mathematics basic facts, with the expectation that words will be learned at home. Teachers pointed out that support at home was varied. Therefore if there was an expectation that 
practising and testing would happen at home, not all students would have the same opportunities, leading to some students being disadvantaged. While it is obvious from student comments that there is home support for many students, there could also be equity issues for those without home support. It was also clear from the students' comments that there were definite variations in methods families employed with regard to the learning and testing of spelling at home. It would be useful to examine where spelling homework fits in the spelling programme. It may be that it is regarded as a supplement to school programmes, or it may be an expectation that teaching and testing will happen at home.

When lists of spelling play a large part in a spelling programme it is possible that perception of ability can be around the ability to memorise and that spelling is mainly a task of memory (Beers et al., 1991). The labelling of a student as good or not good at spelling could imply that the child and the teacher feel that the condition cannot be changed. A teacher pointed out, "(People say) they are either a good speller or not a good speller, and if you are not a good speller then you stay in that I'm not a good speller person box'. Whereas kids can be taught how to spell." Brann (2004) notes this point that judgements can be made about whether students are good or poor spellers through the view of their ability to reproduce words from memory. If a teacher or student feels they are not a good speller it may be viewed that targeting teaching at instructional match will not lead to improvement.

\section{Meta-cognition}

The teachers of the Year 4 student participants felt that some of the more able students did demonstrate meta-cognitive awareness when they approximated words in their drafts. They noted the use of independent transfer of knowledge and of problem-solving. Students' comments backed up teachers' beliefs. For example 
Ethan said "If you know another word that is pretty much like it you might get it right ...". Also his explanation of combining strategies as "mixing them together", displayed his meta-cognitive problem-solving ability.

The teachers pointed out that for many students, scaffolding and prompting by teachers was required to make the links that enabled strategic problem-solving and transference. Certainly the students' comments about their strategies indicated that the lower achieving B Group students required scaffolding to bridge the gap between the explicit teaching of skills and the words they use in their writing. One teacher stated, "I think they have to be taught. What are we teaching if we are not teaching kids how to think."

\section{Feedback on approximations}

The information from students' word attempts can demonstrate whether the student has the necessary phonemic awareness and spelling pattern skills and what needs to be learned (Allcock, 2006). At times, students may use the wrong spelling pattern. For example the sound analysis may be correct but the grapheme selected is not the right one (Brann, 2004). Feedback needs to acknowlege the writing of the correct sounds and also shown the correct spelling pattern for this word (Allcock, 2006). Teachers were asked in the interview (See Appendix L) what feedback they would give students for an attempt of the following words: spowting/spouting and tran/train. Teachers overwhelmly believed that they would firstly praise a student for the attempt of spowting/spouting. Some teachers would acknowledge the correct letters by ticking them above the spelt word, and most teachers would discuss the low/ sound and its various spellings, or the $\mathbf{o} u$ and $\mathbf{o} w$ letter combinations that can be used to write the /ow/ sound. 
According to Allcock (2006), when giving feedback for a student's attempt of tran/train, teachers should acknowledge all the corrrect sounds that have been written and then show how the long /ai/ sound looks on the word train. Four of the teachers would give this feedback, drawing attention to the long /ai/ sound. Two teachers would use sound boxes. Elkonin sound boxes are helpful to assist students hear individual phonemes (Allcock, 2006). The use of sound boxes would not assist students to further their understanding about the the long /ai/ sound, as tran/train is phonetically correct. The teachers also noted that phonographic attention to the spelling pattern and sounds along with analogies to word families such as rain and pain would be very useful analogies to to draw attention to and make links.

\section{Does guessing mean approximating}

A point raised by one of the teachers was the concept of 'guessing'. 'Guess' appear to be a colloquial term used by some teachers and some students who participated in this study. The word 'guess' was used to describe what students did to solve the spelling of a word. I did not get a detailed explanation of what students and teachers mean when they referred to 'guess' but it was used in a similar way to the words 'approximate' and 'invent'.

The word 'guess' may have different interpretations by various students and teachers. Although guessing does not appear to be referred to in literature, it was offered in the choice of strategies in the NEMP question (Crooks et al., 2007). Interestingly, the participating students were asked this question (See Appendix K), and while $33 \%$ of student participants in this study chose 'guessing' as one of the first two strategies they would use out of eight strategy choices, none of the teacher participants (See Appendix M) believed 'guessing' would be in the first two strategy choices of the students. It would be useful to get clarification on what schools believe 
is meant by 'guess'. It would also be interesting to know if it is common belief that it is a useful term for encouraging strategy use.

\section{The impact of hearing and speech difficulties}

Speech inaccuracies were noted as a factor contributing to spelling difficulties. One teacher gave an example saying that if a child said wiv/with or somepink/something they would not hear the correct sounds to write. It was confirmed in the student interviews of the lower achievers, that speech difficulties were having a negative effect on development of accurate spelling.

\section{Use of computers to assist with spelling}

Use of information and communication technology, of which one aspect is use of the computer tool, can supplement traditional ways of teaching and open up different ways of learning (Ministry of Education, 2007). As was discussed in the previous chapter, some of the participating students reported using computers for publishing but none of the 12 students used computers at school for drafting writing. The students' comments indicated that most students did not possess the skills needed to effectively make use the spell-checker tool in processing programs independently. Comments from teachers confirmed the students' reports about students' computer usage and skills.

The interviews revealed two main reasons given by teachers for little computer use in the writing programme. Many classrooms had one or two working computers but some classes did not have computers near the hub of the class activity. Teachers pointed out that when students work on the computers, adult direction is required to teach the skills and supervise the use. Six of the nine teachers saw these access and supervision issues as barriers for regular use of computers in class writing programmes. Some teachers viewed computers as useful tools for students with 
specific learning difficulties. One teacher of juniors noted that the keyboard layout along with the keyboard being in capital letters were barriers for successful use with junior students.

Teachers and students viewed use of computers as a publishing tool. However, it was noted that publishing on a computer could be a lengthy process, with one teacher noting that a child could spend a day publishing a piece of writing. Some teachers themselves published the writing for the students, to enable the students to have a correct and published piece of writing to display. One teacher had her students publish on a regular basis, after they had drafted their writing in their books. One teacher published the students' work in a wiki, which she explained is a controlled blog, to enable opportunity for students' work to be read by a wider audience. Several teachers had computer games available to reinforce spelling. In one class, the computer games were linked to the essential lists (Croft et al., 1998). One school linked the teachers' laptops to interactive whiteboards, through which teachers and students access learning tools, which include spelling practice. One teacher used a spelling skills programme that students could access at home or at the after school study centre.

Discussion about the usefulness of the spell-checker tool for spelling learning drew comments with varied opinions. Some teachers believed a spell-checker was a useful learning tool and others stated an opposite view. Three of the teachers commented on the positive use of a spell-checker. The first teacher stated, "They (students) need the skill for life so why would you deny them that. You would teach them how to do that because it's exactly what we (adults) do on a published piece of work. We check through our red lines." The second teacher agreed, "I would personally think if you are on the computer using it, the tool is in the computer for you 
to utilise and in the real world we are not going to all go running out to our dictionaries when we can go click, click." A third teacher pointed out that the red line is a useful alert and good for spelling awareness. "They see a line comes up and they will correct themselves at that point because they know it's a mistake because the computer draws their attention straight away." These teachers view the spell-checker as useful for teaching students about monitoring and checking. Others felt it was a hindrance to the learning process.

On an opposing view, one teacher believed that when errors are pointed out on the spell-checker, it is detrimental to the students' development of their own monitoring. "I think writing on the computer is a hindrance if you are doing word processing, because it actually tells you if you've got it wrong. Or they (the students) might have put they instead of the and it's not going to pick that up."

Teachers' comments of the advantages and disadvantages of word processing on the computer and use of computer spell-checkers, lead to the conclusion that with differing opinions on the place of ICT in teaching writing and spelling there will be varying use of the use of computers in class programmes. These variations of opinion, along with the difficulty with supervision and classroom access, may contribute to these Year 4 students having only some or little opportunity to practise the use of spelling strategies in an "e-learning" (Ministry of Education, 2007, p. 38) environment.

\section{Conclusions from teachers' and students' views}

Chapter 5 describes the strategies and knowledge teachers believe to be important for students to spell words in writing. This chapter, in seeking to answer research question 4, describes how teachers' beliefs about what is important compare with the strategies these Year 4 students used. 
Teachers believe that students use visual and letter/sound information to spell the words they need in the writing and provide three main learning programme contexts for students to learn to spell. They are: 1) classroom writing lessons, 2) words study lessons and 3) the memorising of lists of words.

1. Teachers generally believe that in classroom writing lessons, students' draft writing should contain correct words that students already know how to spell, with use of approximations for those they do not. After the draft is written, teachers expect that Year 4 students will identify attempted words to check, and correct words using prompts from teachers towards appropriate spelling resources.

2. Word study lessons are an important component and include direct teaching about spelling patterns and morphological rules.

3. Selection of words for students to memorise are also viewed as an important aspect and used by all teachers. There is an expectation that learning and testing of the words will to be part of the homework routine.

There was evidence that the A Group students made connections between the words study learning and the words they needed in their writing. Students reported varying methods of learning and testing at home. Some teachers believe the list learning method may not be matched to student need, and this was backed up with comments of the lower achieving students who were frustrated when they had learned words only to find they could not recall them in their writing.

Terminology such as 'sounding out' and 'guessing' were terms used by students and teachers when describing working out words through use of hearing sounds and recording the letters. The terms appear to have many differing interpretations. Consequently, they could cause confusions if used when teaching 
spelling strategies. Therefore if these terms are used in classroom practise, there needs to be agreement by all on their meaning and use.

Access for students to use computers at school was variable depending on availability of resourcing. Teachers and students spoke of the use of computers for some publishing of writing and spelling games. Home use, was reported by students as dependent on availability with some students having access and others having none. Generally teachers did not view word processing on computers as useful, although some teachers believed the spell-checker tool would be of use for students if computers were more accessible, along with enough supervision. Only one of the 12 students had workable knowledge of a spell-checker, having learned the skill from a peer. The use of e-learning to enhance spelling through composing of writing on a computer, was not generally viewed as valuable.

Teachers believed that the more able students using meta-cognitive awareness to make spelling links. As has been discussed in Chapter 4, the strategies students use to problem-solve new words differed greatly between the $A$ and the $B$ Groups. The lower achieving students generally used one of either visual of phonographic strategies. The average achievers added the use of morphological strategies and combinations of all three. Teachers noted that scaffolding to make clear links is required for less able students. The significance of the teacher beliefs about the need for scaffolding may not be fully realised by them.

Chapter 6 concludes the study by summarising the key findings of this study and makes recommendations for teaching spelling. 


\section{CHAPTER 6}

\section{Conclusion}

Chapter 4 described the spelling knowledge and strategies used by the underachieving and average achieving Year 4 students while Chapter 5 offered the teachers' perspectives on spelling and compared their views with student findings. This final chapter summarises the key findings about spelling that emerged from the student and teacher data and it concludes with recommendations for teaching to improve students' spelling.

The first significant finding from this study, is that while the average achieving A Group students showed use of visual, phonographic and morphological strategies and combinations of these, the lower achieving group of students used mainly visual strategies for known words and phonographic strategies to solve unknown words. Very little morphological knowledge was used and there was very little use of combining the strategies. The lower achieving B Group students were not independently making the links between strategies to generalise from prior knowledge and "figure out the logic of words" (Phenix et al., 1991, p. 18). The ability to link prior knowledge and use a combination of strategies is essential when students are attempting to spell challenging words. As one teacher pointed out, "Without those fragments tying up together, you've got loops. You've got learning knowledge missing."

A second significant difference between the two groups of students was that the lower achieving B Group students did not make the connections between the three learning programming contexts: class word study, learning words from their personal lists, and classroom daily writing lessons. The learning in one context was 
not automatically transferred into another. This resulted in isolated pockets of learning or "items of knowledge" Clay (1991, p. 328). When this happens, the value of word study and words learned, would not be fully harnessed for use in independent problem-solving in the classroom writing lessons.

Finding instructional match and making the explicit links is crucial to these lower achieving students' learning progress, but is more difficult to ascertain than for successful students. It begins with examination of students' writing. Through teachers analysing the words students have approximated in their continuous writing, and discussing with the students the strategies they have used, valuable information will be revealed as to the students' individual zones of proximal development.

Instructional match needs to include the following:

1. Close examination of strategies used by individual students in their draft writing in class writing lessons and identification of the strategies that are required next.

2. Fostering meta-cognitive awareness towards strategic problem-solving. Fostering the use of techniques such as combining strategies and choosing useful strategies. Deliberate acts of teaching to make explicit links between prior knowledge and the visual, phonographic and morphological strategies.

3. Deliberate acts of teaching to scaffold the making of connections between the three learning programming contexts, of classroom word study, personal spelling lists and classroom writing lessons. 


\section{Recommendations}

The following are the recommendations made as a result of this research:

1. Teachers should analyse students' approximations in their draft writing to search for current use of strategies and next steps required in strategy use.

2. Teachers need to foster meta-cognitive awareness towards use of a problemsolving approach to spelling.

3. Teachers need to make explicit links between students' prior knowledge and the use of visual, phonographic and morphological strategies and their combinations.

4. Teachers need to scaffold the connections between the three learning contexts of classroom word study, personal spelling lists and classroom writing lessons. Teaching in these contexts needs to reflect the students' needs that have emerged through analysis of students' draft writing.

5. Schools need to clarify terminologies such as 'sounding out' and 'guessing' and if they are to be used, agree on a common understanding between teachers and students.

6. Peers could be used to scaffold students' learning through sharing ways of problem-solving words and in gaining computer skills.

7. Schools could explore ways that e-learning could be used to support learning of spelling in the context of writing through word processing on a computer. A consideration of the school's philosophy of computer use for word processing and the use of the spell-checker tool would be timely.

8. It would be useful to trial a classroom programme using recommendations 1-4. This could be implemented with a group of Year 3 or 4 students who are achieving below expected level in the spelling component of writing. 


\section{References}

Ager, R. (2003). Information and communication technology in primary schools:

Children or computers in control? (2nd ed.). London: David Fulton.

Allal, L. (1997). Learning to spell in the classroom. In C. A. Perfetti, L. Rieben \& M.

Fayol (Eds.), Learning to spell: Research, theory, and practice across languages

(pp. 129-150). New Jersey: Lawrence Erlbaum Associates.

Allcock, J. (2006). Switch on to spelling. Auckland: Heinemann.

Beers, C. S., \& Beers, J. W. (1991). A developmental basis for spelling instruction. In D.

Booth (Ed.), Spelling links: Reflection on spelling and its place in the curriculum. Ontario: Pembroke.

Bereiter, C., \& Scardamalia, M. (1987). Composing and writing. In R. Beard (Ed.), Teaching literacy balancing perspectives (pp. 155-175). Abingdon: Hodder \& Stoughton Educational.

Brann, B. (2004). The Brann analysis grid for spelling: A resource for analysing spelling attempts (4th ed.). Queensland: B.M.B. Educational Consultancy.

Brann, B., \& Hattie, J. (1995). Spelling instruction in primary schools. New Zealand Journal of Educational Studies, Vol. 30(1), 39-49.

Brown, J., \& McLean, N. (2010). Developing speech. Ministry of Education: Special Education. Lower Hutt.

Bruning, R. H., Schraw, G. J., \& Ronning, R. R. (1999). Cognitive psychology and instruction (3rd ed.). New Jersey: Prentice-Hall.

Bryman, A. (2004). Social research methods. Oxford: Oxford University Press.

Clarke, S., Timperley, H., \& Hattie, J. (2003). Unlocking formative assessment: Practical strategies for enhancing students' learning in the primary and intermediate classroom: New Zealand edition. Auckland: Hodder. 
Clay, M. M. (1991). Becoming literate: The construction of inner control. Auckland: Heinemann Education.

Clay, M. M. (1993). Reading recovery: A guidebook for teachers in training. Auckland: Heinemann.

Croft, C. (2004). Monitoring progress in spelling using developmental information. Wellington: New Zealand Council for Educational Research.

Croft, C., \& Mapa, L. (1998). Spell-write: An aid to spelling and writing. Wellington: New Zealand Council for Educational Research.

Croft, C. (1998). Teachers manual for spell-write: An aid to writing, spelling and word study. Wellington: New Zealand Council for Educational Research.

Crooks, T., Flockton, L., White, J., NEMP, University of Otago, \& Ministry of Education. (2007). National education monitoring project: Writing assessment results 2006. Dunedin: University of Otago Educational Assessment Research Unit.

Dahlberg, L., \& McCaig, C. (2010). Practical research and evaluation: A start to finish guide for practitioners. London: Sage Publications.

Davis, A. (2007). Teaching reading comprehension. Wellington: Learning Media.

Denzin, N., \& Lincoln, Y. (Eds.). (2005). The SAGE Handbook of qualitative research. (3rd ed.). Thousand Oaks CA: Sage Publications.

Department of Education Tasmania (2007). English learning area. Retrieved December 6,2009 , from www.education.tas.gov.au/curriculum/standards/english/english/teachers/glossary Dickie, J. (2008). Developing students' metacognitive strategies through persuasive writing: Resource developed for WELD. Wellington: Victoria University.

Emmitt, M., Pollock, J., \& Limbrick, L. (1996). An introduction to language and learning (New Zealand ed.). Melbourne: Oxford University Press. 
Gentry, J. R. (1987). Spel... is a four letter word. Auckland: Scholastic.

Gentry, J. R. (1991). Developmental aspects of learning to spell. In D. Booth (Ed.), Spelling links: Reflections on spelling and its place in the curriculum. Ontario: Pembroke.

Graham, S., \& Harris, K. (2006). Preventing writing difficulties: Providing additional handwriting and spelling instruction to at-risk children in the first grade. Teaching Exceptional Children 38(5), 64-66.

Graves, D. H. (2003). Writing: Teachers and children at work. Portsmouth, NH: Heinemann.

Hood, H. R. (2000). Left to write too: Developing effective written language programmes for younger learners (2nd ed.). Palmerston North: Dunmore.

Invernizzi, M., \& Hayes, L. (2004). Developmental-spelling research: A systematic imperative. Reading Research Quarterly, 39(2).

Jackson, C., Konza, D. M., Ben-Evans, J., \& Roodenrys, S. (2003). Spelling accuracy for secondary students with spelling difficulties: Using phonetic codes and technology. Australian Journal of Learning Disabilities, 8(1), 23-29.

Johnson, B., \& Christensen, L. (2008). Educational research: Quantitative, Qualitative, and mixed methods approaches (3rd ed.). Los Angeles CA: Sage.

Lai, M., McNaughton, S., Hsiao, S., Mose, K., Hall, A., Knight, N., et al. (2010). Sustaining improvements in student achievement: Myth or reality? Set: research information for teachers (1), 10-17.

Miles, M., \& Huberman, A. M. (1994). Qualitative data analysis. Thousand Oaks, CA: Sage Publications.

Ministry of Education. (1994). English in the New Zealand curriculum. Wellington: Learning Media. 
Ministry of Education. (1999). Report on the literacy taskforce. Wellington: Crown.

Ministry of Education. (2003). Effective literacy practice in years 1 to 4 . Wellington: Learning Media.

Ministry of Education. (2007). The New Zealand curriculum for English-medium teaching and learning in years 1-13. Wellington: Learning Media.

Ministry of Education. (2009a). The national education goals. Retrieved November 3, 2009, from

http://www.minedu.govt.nz/NZEducation/EducationPolicies/Schools/PolicyAndStra tegy

Ministry of Education. (2009b). The New Zealand curriculum exemplars. Retrieved November 2, 2009, from http://www.tki.org.nz/r/assessment/exemplars/eng/character/index_e.php Ministry of Education. (2009c). The New Zealand Curriculum Reading and Writing Standards for years 1-8. Wellington: Learning Media.

Ministry of Education. (2009d). asTTle: Assessment tools for teaching \& learning - he punaha aromatawi mo te whakaako me te ako. Retrieved September 28, 2009, from http://www.tki.org.nz/r/asttle/index e.php

Ministry of Education. (2010a). The literacy learning progression: Meeting the reading and writing demands of the curriculum. Wellington: Learning Media.

Ministry of Education. (2010b). Sounds and words: Spelling. Retrieved October 10, 2010, from http://soundsandwords.tki.org.nz/Spelling Ministry of Education. (2010c). Schooling improvement. Retrieved October 15, 2010, from http://www.minedu.govt.nz/Boards/SupportForBoards/Schoolinglmprovement.aspx 
Ministry of Education. (2010d). The New Zealand Curriculum Exemplars. Retrieved October 8, 2010, from

http://www.tki.org.nz/r/assessment/exemplars/eng/matrices/matrx trnspoet srfce e.php

Ministry of Education. (2010e). e-asTTle: Writing indicators. Retrieved October 8, 2010 from http://e-asttle.tki.org.nz/resources/Teacher-resources

Naenae LEAP Schooling Improvement Cluster. (2005). A time when I was scared.

Writing test adapted from http://e-asttle.tki.org.nz/resources/Teacher-resources

Patton, M. (2002). Qualitative research and evaluation methods (3rd ed.). Thousand Oaks: Sage Publications.

Phenix, J., \& Scott-Dunne, D. (1991). Spelling instruction that makes sense. Ontario: Pembroke.

Reason, R., \& Boote, R. (1994). Helping children with reading and spelling. London: Routledge.

Silverman, D. (2001). Interpreting qualitative data (2nd ed.). London: Sage Publications. Smith, J. W. A., \& Elley, W. B. (1997). How children learn to write. Auckland: Longman. Smith, P. (2010). To find or to fix: Effective teacher response to error in early literacy learning. Set: research information for teachers (1), 28-36.

Snowling, M., \& Stackhouse, J. (1996). Dyslexia: Speech and language: A practitioner's handbook. San Diego, CA: Singular.

Stake, R. (2000). Case studies. In N. Denzin \& Y. Lincoln (Eds.), Handbook of qualitative research (2nd ed., pp. 435-454). Thousand Oaks: Sage Publications.

Tudge, J. (1990). Vygotsky, the zone of proximal development, and peer collaboration: Implications for classroom practice. In L. C. Moll (Ed.). Vygotsky and education: 
Instructional implications and applications of sociohistorical psychology. New York: Cambridge University Press.

Walsh, M. (2001). Research made real: A guide for students. Cheltenham: Nelson Thornes.

Vercauteren, D. (2008). Feedback in primary classrooms. Set: research information for teachers (3), 25-29.

Ysseldyke, J., \& Christenson, S. (2002). Functional assessment of academic behaviour: Creating successful learning environments. Longmont, Colorado: Sopris West. 


\section{Appendix A}

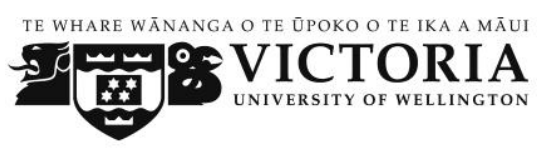

\section{Letter of explanation for principals}

\section{Research Project: Spelling in the context of writing}

This research has been assessed and approved by the Victoria University Faculty of Education Ethics Committee.

\section{Dear}

I am enrolled in the Master of Education course at Victoria University of Wellington. This year I am undertaking a research project for my thesis.

Through my research I am endeavouring to find out more about what strategies students use in their spelling while writing. I am interested in asking year 4 learners and their teachers what they know about spelling strategies. I am seeking to discover, from the students' own view point, what strategies helps students spell words they are not sure of and how they learn words so they can use them in the future. I am interested in finding out from teachers what they believe is important to learn about spelling and how they go about ensuring students gain useful strategies.

I plan to work in three schools and would like your school to be one of the three in the study. I am seeking your permission and the Board of Trustees' permission. I would like to interview a number of Year 4 students and their current and previous teachers. I will be seeking your assistance in finding suitable student participants: Eight Year 4 students, four who are achieving at average and four at below average level in writing, including spelling. I will also need to analyse students' writing samples and observe them at work in their classroom for a short period of time. I would also need to access past records to note past interventions, for example reading recovery.

The time commitment for each teacher interview would be about $1 \frac{1}{2}$ hours for each teacher. I would need to administer a writing asTTle test and conduct two interviews per student. All interviews would be conducted at school. 
Before analysis, teachers will be given transcripts of the interview for checking. A summary of the student interviews will be read to the individual students for checking. Only my supervisor and I will have access to the research records. Data will be kept confidential.

If teachers, students or their parents do not wish to participate, this will not in any way affect our future working relationship.

No names or identifying features will be used in the reporting of the study.

Pseudonyms will be used. Care will be taken to protect the identity of participants in data used to produce written and oral reports as a result of the study. Data will be stored in a locked file and destroyed after 3 years.

Findings will be collated and analysed for patterns and trends. Once analysed, the collated findings will be shared with you and Board of Trustees, and later the schools in our cluster of schools. The research will be written up in a thesis and may in future be presented in a journal or at a seminar. It is hoped that this research will contribute to the knowledge educators have about how children think about their learning in spelling.

My intended procedure is:

1. Select possible participants.

2. Seek permission from teachers, students and parents.

3. Observe participating students in class and view work. Collect samples of current writing.

4. Collect records of previous interventions eg if they have had Reading Recovery.

5. Administer asTTle test. Interview students in pairs immediately after test.

6. Interview students in pairs another day.

7. Interview teachers.

8. Give transcripts back to teachers for checking.

9. Collate data.

10. Report collated results to participants. 
11. Write up research.

12. Share with schools.

A written explanation is being provided for the teachers, parents and students and written permission will be sought from them before commencing the research.

Students, parents and teachers would have the right to withdraw from the study up to the time of data analysis.

I do hope you will be able to allow your school to be part of this study. If you have any questions about this study I would be happy if you contacted me at home on 9389510 or email: penteco@paradise.net.nz my supervisor Dr John Dickie on 4639767 or email: John.Dickie@vuw.ac.nz

If you agree to be part of this study, please fill in the enclosed form and return by reply paid envelope.

Thank you very much for your assistance.

Helen Pentecost 


\section{Appendix B}

Consent form for principals

Research: Spelling in the context of writing

I have read Helen Pentecost's introductory letter explaining her research and I agree to this school being part of the study.

I understand:

- Teachers and students do not have to take part in this research.

- Written permission will be gained from each participating teachers.

- Written permission will be gained for each student and his/her parent for their participation and collecting of samples of their writing.

- Interviews and observations will be conducted at the school.

- Students will be interviewed in pairs.

- Names of participants and schools will be kept confidential. Pseudonyms will be used for teachers, students and schools.

- The teacher and student interviews will be audio-taped then transcribed. 
- Teachers will have the opportunity to check the transcript for accuracy and make changes.

- Samples of students' writing will be collected and may be published as part of the research findings. Samples will be kept confidential. Permission will be sought.

- The data will be kept in a locked file in researcher's home and destroyed after three years.

- Participants can withdraw without giving a reason up to the final point of data collection.

- The research findings will be written in a thesis and may be published and shared with other interested people including the Board of Trustees and schools.

I agree that my school can be part of the study.

I would like to receive a summary of the results of the research when it is completed.

School:

Name: Position:

Signature: Date: 
TE WHARE WĀNANGA O TE ŪPOKO O TE IKA A MĀUI

\section{Appendix C}

\section{Letter of explanation for teachers}

\section{Research Project: Spelling in the context of writing}

\section{This research has been assessed and approved by the Victoria University Faculty of Education Ethics Committee.}

\section{Dear}

I am enrolled in the Master of Education course at Victoria University of Wellington. This year I am undertaking a research project for my thesis.

Through my research I am endeavouring to find out more about what strategies students use in their spelling while writing. I am interested in asking year 4 learners and their teachers what they know about spelling strategies. I am seeking to discover, from the student's own view point, what strategies helps students spell words they are not sure of and how they learn words so they can use them in the future. I am interested in finding out from teachers what they believe is important to learn about spelling and how they go about ensuring students gain useful strategies.

I would like to interview a number of Year 4 students and their current and previous teachers. The participating students will be achieving at average or below average level in writing including spelling. I will need to analyse students' writing samples and observe them at work in their classroom for a short period of time. I will administer an asTTLe writing test to the group and talk to them afterwards about their spelling in their writing.

I am seeking permission for you to be one of the teachers in the study. The time commitment for the teacher interview would be about $1 \frac{1}{2}$ hours. I would like to have permission to audiotape the interview. 
Before analysis, teachers will be given transcripts of their interview for checking. A summary of the student interview will be read to the individual students for checking.

Only my supervisor and I will have access to the research records. Data will be confidential. All the names of students and teachers will not be identified in the report. Pseudonyms may be used in the reporting of the study. Data will be stored in a locked file and destroyed after 3 years.

Findings will be collated and analysed for patterns and trends. It is hoped that this research will contribute to the knowledge educators have about how children think about their learning in spelling. The findings will be shared with this school's teachers and Board of Trustees and the schools in our cluster. The findings will be written in my thesis which may be shared with interested educators.

If you agree to be part of this study, you would have the right to withdraw, up to the time of data analysis. If you have any questions about this research I would be happy if you contacted me at home on 9389510, email: penteco@paradise.net.nz or my supervisor Dr John Dickie on 4639767, email: John.Dickie@vuw.ac.nz .

I do hope you will be able to be part of this study. If you do not wish to be part of this study, this will not any way change any working relationship we have. If you agree to participate, please fill in the enclosed form and return by reply paid envelope.

Thank you very much for your assistance.

Helen Pentecost 


\section{Appendix D}

TE WHARE WĀNANGa o TE ŨPOKO O TE IKA A MĀUI

Consent form for teachers

\section{Research: Spelling in the context of writing}

I have read and understood Helen Pentecost's introductory letter explaining her research and

I understand:

- Names of participants and schools will be kept confidential. Pseudonyms will be used.

- The interviews will be audio-taped then transcribed.

- I will have the opportunity to check the transcript for accuracy and make changes.

- Data collected will be seen only by the researcher and her supervisor.

- Data will be kept securely in a locked file in researcher's home and destroyed after three years.

- The collated research findings may be published and will be shared with other interested people including the Board of Trustees and schools. 
- I understand I can withdraw from the study up to the time of final data collection.

I agree to be one of the teacher participants in the study. I would like to receive a summary of the results of the research when it is completed.

Name:

Date:

Signature: 


\section{Appendix E}

\section{Letter of explanation for parents and caregivers. \\ Research Project: Spelling in the context of writing}

\section{This research has been assessed and approved by the Victoria University Faculty of Education Ethics Committee.}

Dear

My name is Helen Pentecost. I am a teacher who is currently enrolled in the Master of Education course at Victoria University of Wellington. This year I am undertaking a research project for my thesis.

Through my research I am endeavouring to find out more about what strategies students use in their spelling while writing. I am interested in asking year 4 learners and their teachers what they know about spelling strategies. I am seeking to discover, from the student's own view point, what strategies helps students spell words they are not sure of and how they learn words so they can use them in the future.

I have obtained permission from the Principal and the Board of Trustees for my research to include students and teachers from this school. I would like to interview a number of Year 4 students in pairs, including your child . I am interested in finding out your child's own ideas about what he/she knows. I will also need to analyse students' writing samples and observe them at work in their classroom for a short period of time. I would also note any previous school programmes such as reading recovery. All interviews will be conducted in school time at school.

Only my supervisor and I will have access to the research records. Data will be kept confidential and participants will not be identified. No names or identifying features 
will be used in the reporting of the study. Pseudonyms will be used. Data will be stored in a locked file and destroyed after 3 years.

Findings will be collated and analysed for patterns and trends. The collated report written up as a thesis. Findings will be shared with the participating parents, the teachers and the Board of Trustees of the school and later our nearby cluster of schools. It is hoped that this research will contribute to the knowledge educators have about how children think about their learning in spelling.

I do hope you will agree to allowing your child to be part of this study. If you have any questions about this study I would be happy if you contacted me at home on 9389510 or email: penteco@paradise.net.nz or my supervisor Dr John Dickie on 4639767 or email John.Dickie@vuw.ac.nz .

If you agree to your child being part of this study, please fill in the enclosed form and return by reply paid envelope.

Thank you very much for your assistance

Helen Pentecost 


\section{Appendix F}

Consent form for parents and caregivers

\section{Research: Spelling in the context of writing}

I have read Helen Pentecost's introductory letter explaining her research and I agree to my child being part of the study.

I understand:

- My child will be interviewed with one other, and observed in class.

- Interviews and observations will be conducted at the school.

- Samples of my child's writing will be collected.

- Records of previous school programmes such as reading recovery will be noted.

- My child and the school will not be identified in the study.

- Permission for this study has been gained from the Principal and Board of Trustees.

- The information will be kept in a locked file.

- My child does not have to take part and can withdraw from the project. 
- The research findings may be published and will be shared with other interested people including the Board of Trustees and schools.

I agree to my child participating in the study.

I would like the opportunity to hear feedback of the results of the research when it is completed.

Name:

Signature: Date: 


\section{Appendix G}

Letter of explanation for students

Research Project: Spelling in the context of writing

\section{Dear}

I am a teacher who works in several schools and am interested in children's writing. I am doing some research to find out about spelling. Your principal has given permission for me to work in your school. I am interested in finding out from you and your teachers what you know about spelling. Through asking children such as you what you think, I hope to find out more about what you know about words, what helps you to write words you are not sure of, and how you learn words to use. This will help teachers know more about how best to teach children.

If you agree to be one of the students in my study, I will also need to ask you to write a story and then talk to you and a partner about what you know about some of the words and how you spell them. I will talk to you and a partner out of the class two times. I will also need to come into you class once when 
you are writing. Any work you do for the study will be in school time, not play time.

You would be helping my study a lot if you agree to participate. I do hope you can do this. It would help me and the teachers to know more about how children learn.

I am seeking your permission to take part in this study. If you agree to be part of this study, please fill in the form.

Thank you very much, Helen Pentecost 


\section{Appendix H}

Consent form for students

Research: Spelling in the context of writing

I have read Helen Pentecost's letter explaining her research and I agree to be part of the study.

I understand:

- I will do some writing and talk about it.

- Some of my writing will be photocopied and taken away and may be published without my name.

- I will talk in a small group about my writing.

- I will do all of this in class time.

- My name will not be written in the report.

- My ideas will be written in the report, which may be 
published and may be shared with teachers.

- I have the right to change my mind about taking part in the research.

School:

Signature:

Date: 


\section{Appendix I}

\section{Interview Schedule 1 for students}

Immediately after working on writing sample.

1. Which words here do you know are spelt correctly?

2. How do you know?

3. When you wrote that word, how did you know how to write it?

4. Which words were you unsure how to write?

5. What did you do when you needed to write that word?

6. What do you do to check that word?

7. Did/Would it help?

8. What do you recall that you have been taught at school that helped you with spelling your words for this writing?

9. What do you recall that you have learned at times or places other than at school that has helped you with spelling your words for this writing? 


\section{Appendix J}

\section{Interview schedule 2 for students}

1. Do you know some things about some words that help you with spelling other words?

2. What do you know about spelling rules, or how words are written?

3. What does not work well?

4. How do you know if you are on the right track when spelling a word?

5. What is something that works well for you when you are spelling a word that you don't know or are unsure of?

6. Do you think back to previous learning to help? If so how do you do this? What have you used?

7. How does the teacher help you with your spelling in your writing? What feedback do you get from teachers about your spelling in your writing?

8. How does a computer help in spelling? Have you used a computer spell-checker? Did it help?

9. Is correct spelling important? Why? When?

10. How do you know if you are improving in your spelling?

11. What are ways that you increase your vocabulary?

12. Do you have a list of words to learn to spell?

13. Where do you get the words from?

14. What do you do with the words to help you learn them?

15. What do you do at school to learn how to spell words?

16. What do you do at home to learn how to spell words?

17. How would you like to be taught spelling? Have you ideas that could help teachers?

18. What would you like teachers to do to help you learn spelling?

19. What age were you when you knew your letter names? Did you learn them at school?

20. What do you think letters are used for in writing?

21. Did you know any rhymes before you came to school? Which ones?

22. What rhymes have you learned at school?

23. How many syllables are in ? (personal word(s) from writing)

24. How many sounds are in ? (personal word(s) from writing) 
25. What sounds can you hear at the beginning, ( also middle and end) of the word ? (Personal word)

26. Is there anything else you would like to tell me about spelling? 
Child to complete. Researcher to read to child

\section{Likert type scale:}

heaps quite a lot a little not at all
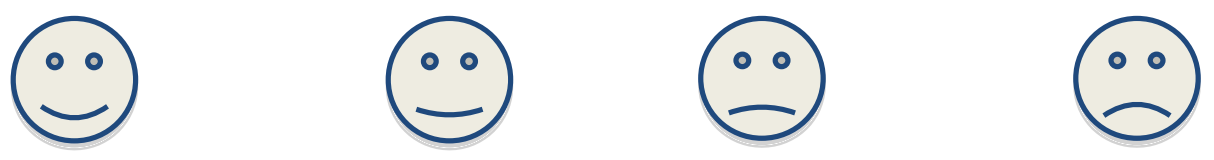

27. Do you get opportunity to learn new words at school?
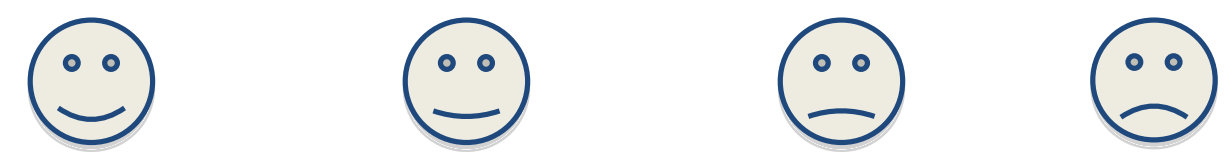

28. Do you learn your words with any other children at school?
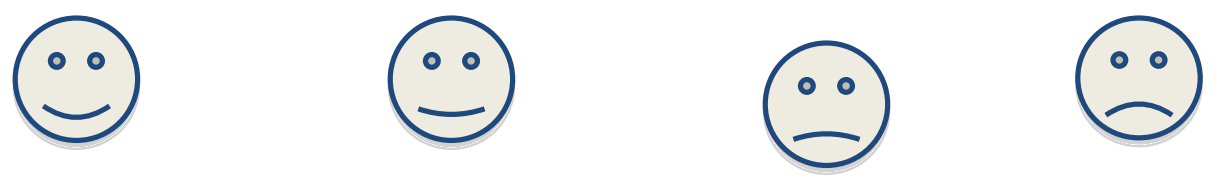

29. Do you learn words at home?
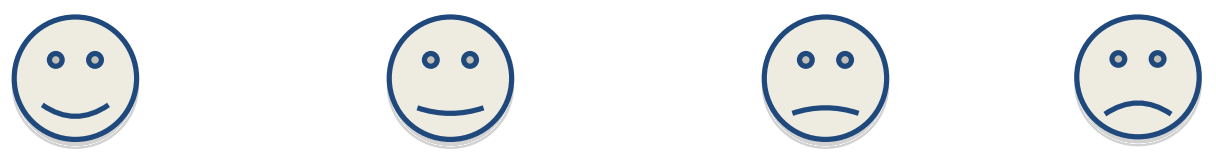

30. When you have learnt a word can you then spell it correctly when you are writing?
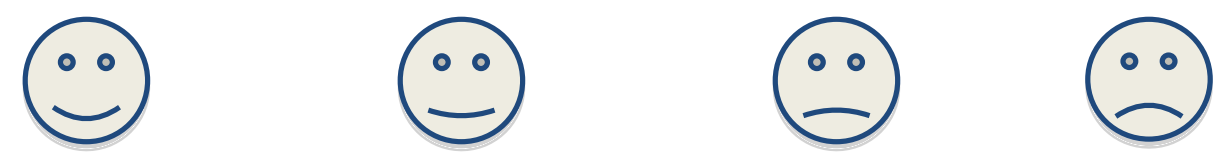


\section{Appendix K}

\section{Interview Schedule 3 for students}

Taken from NEMP 2006. Researcher to read aloud and student to tick boxes.

1. What do you usually do when you can't spell a word in writing? (Choose up to two things from eight options).

\begin{tabular}{|l|l|}
\hline & Use a dictionary \\
\hline & Try then check out later \\
\hline & Sound out the word \\
\hline & Guess \\
\hline & Ask the teacher \\
\hline & Ask a friend \\
\hline & Use another word \\
\hline & Use computer spell checker \\
\hline
\end{tabular}




\section{What do people need to be good writers?}

(Choose up to three from ten options).

\begin{tabular}{|l|l|}
\hline & Use their imagination \\
\hline & Be willing to try things out \\
\hline Go back and check their work \\
\hline Learn how to use punctuation \\
\hline Know how to spell words \\
\hline Write neatly \\
\hline Read a lot \\
\hline Talk about their work with others \\
\hline
\end{tabular}


From NEMP 2006 (likert type scale)

heaps quite a lot

a little

not at all
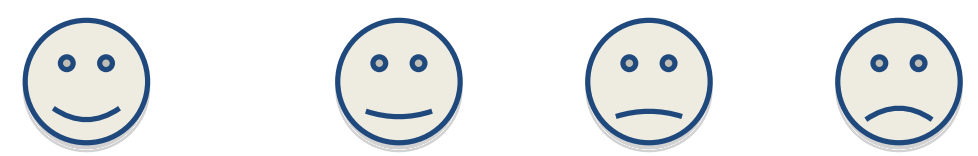

3. How good do you think you are at writing?
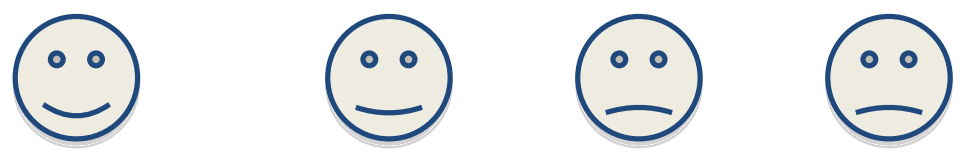

4. How good do you think you are at spelling?
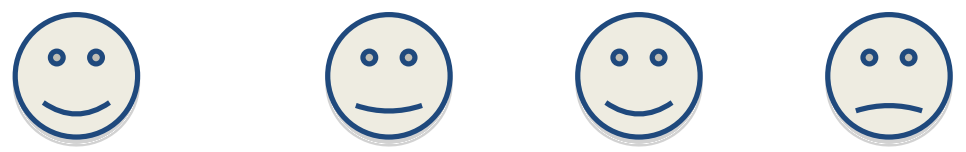

5. How often do you write using a computer at school?
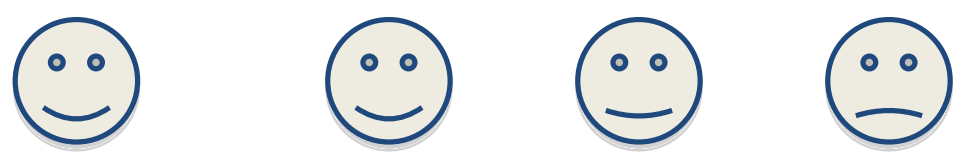

6. How often do you write using a computer at home?
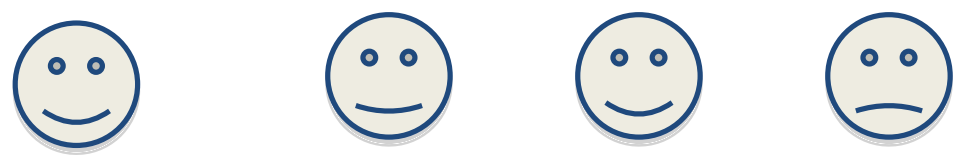


\section{Appendix L}

\section{Interview Schedule 1 for teachers}

1. What do you believe are the components of an effective spelling programme?

2. What are the barriers to an effective spelling programme happening?

3. How do you believe young children learn to spell?

4. What do you believe works for students to learn to spell words? How do you know?

5. What doesn't work? How do you know?

6. Does your programme include spelling lists? What is the expectation of the student with the list? What is the value you see for student learning?

7. Is correct spelling important? Why? When?

8. Tell me about the methods you use to teach spelling?

9. How much time per week should be spent on learning about spelling?

10. How do you teach students to monitor their spelling in writing?

11. How do you deal with spelling errors in children's writing?

12. If a student wrote spowting for spouting, what feedback might you give?

13. If a student wrote tran for train, what feedback might you give?

14. Do you see active meta-cognition happening for a student when spelling a word in writing, or learning a word?

15. Do you see transfer of knowledge and strategies in student's spelling from one piece of learning to another? Can you give an example? How do you encourage this transfer?

16. Where do you see the place of the computer in writing and spelling?

17. What do you believe students do to spell a word they don't know?

18. Is there anything else you would like to tell me what you have noticed about students' spelling in writing? 


\section{Appendix M Interview Schedule 2 for teachers}

Numbers 1 and 2 taken from NEMP (2006).

1. What do your students usually do when they can't spell a word in writing? (Choose up to two things from eight options).

\begin{tabular}{|l|l|}
\hline & Use a dictionary \\
\hline & Try then check out later \\
\hline & Sound out the word \\
\hline & Guess \\
\hline & Ask the teacher \\
\hline & Ask a friend \\
\hline & Use another word \\
\hline
\end{tabular}

2. What do people need to be good writers?

(Choose up to three from ten options).

\begin{tabular}{|l|l|}
\hline & Use their imagination \\
\hline & Be willing to try things out \\
\hline & Go back and check their work \\
\hline & Learn how to use punctuation \\
\hline Know how to spell words & Write neatly \\
\hline & Read a lot \\
\hline & Talk about their work with others \\
\hline & Like writing \\
\hline
\end{tabular}




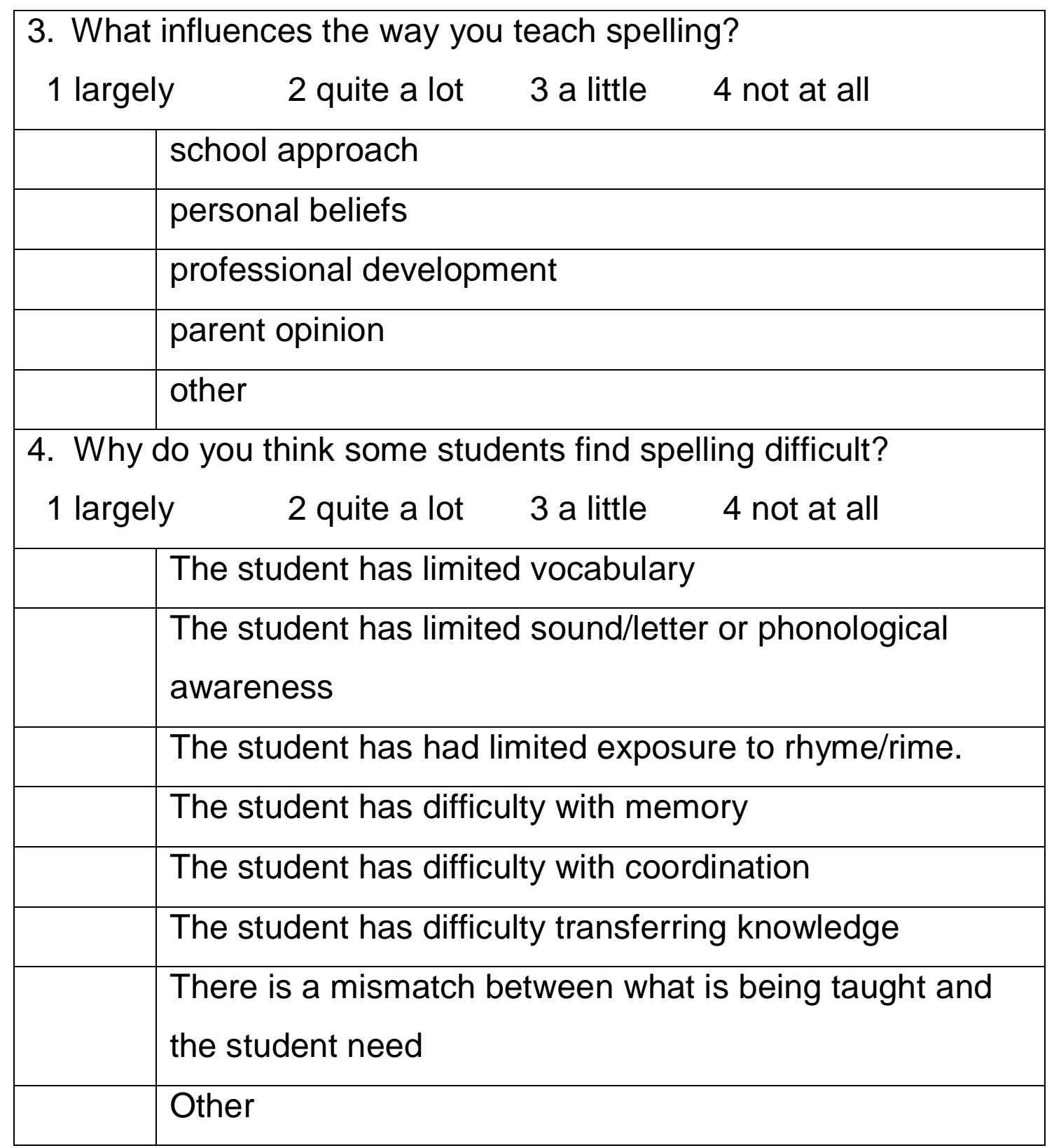


Owner: Naenae LEAP Schooling Improvement Cluster (adapted 2005 from asTTle: http://e-asttle.tki.org.nz/resources/Teacher-resources

Appendix N

\section{A Time When I was Scared}

The Journal of Young People's writing is always looking for stories to publish. In their next journal they want to include stories about scary things that have happened in children's lives.

\section{Think about a time in your life when you have been scared.}

To make sure the readers get an idea of what it was like for you, you will need to include lots of details about how you felt, where you were, who else was there and what happened.

Write a recount about a time when you were scared.

\section{Hints}

- Plan your recount in the planning space

- Include details of who, what, when, where and how so that you can help your readers get a good idea of what this time was like for you.

- Make sure you think about the order of your story so the reader can follow your story easily.

- Remember to write about how you were feeling, what were you thinking to yourself, as well as what happened.

- Hook the reader's attention with an interesting beginning and think of a good way to end your recount. 
- Organise your writing into sentences and paragraphs

- Use interesting language to make your writing interesting and vivid for the reader.

- Use the time at the end to check and edit your writing, paying attention to grammar, punctuation and spelling.
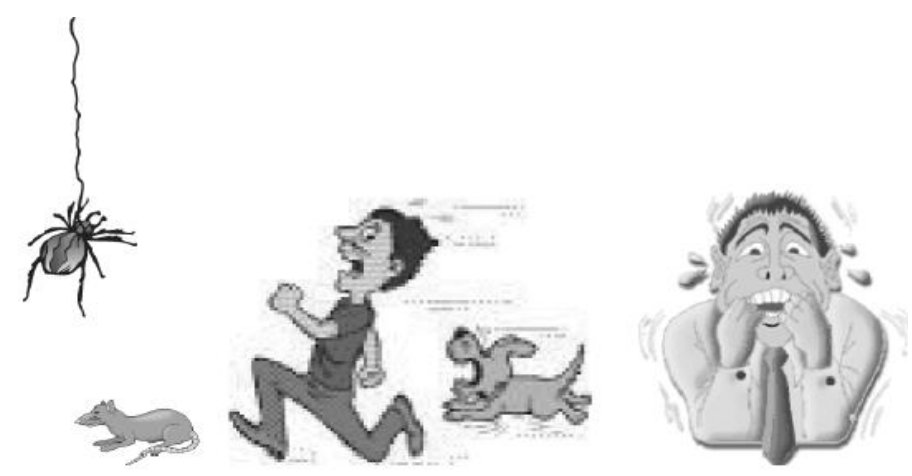


\section{Appendix 0}

\section{Essential Words}

\section{for Spelling and Writing}

The 290 words in this section are used most often when you write. Together, they make up about three-quarters of most writing, so they are important.

These words have been arranged in alphabetical order and put in 7 lists according to how often they are used. The words in List 1 are used most often, the words in List 2 next most often, and so on. Because they are used so often, it is very important that you learn to use and spell each one.

Essential List 1 (10 Words; $25 \%$ of Writing)

$\begin{array}{lllll}\text { a } & 1 & \text { it } & \text { the } & \text { was } \\ \text { and } & \text { in } & \text { my } & \text { to } & \text { we }\end{array}$

Essential List 2 (20 Words; $15 \%$ of Writing)

$\begin{array}{lllll}\text { at } & \text { had } & \text { of } & \text { that } & \text { up } \\ \text { but } & \text { he } & \text { on } & \text { then } & \text { went } \\ \text { for } & \text { is } & \text { she } & \text { there } & \text { when } \\ \text { got } & \text { me } & \text { so } & \text { they } & \text { you }\end{array}$

Essential List 3 ( 30 Words; $10 \%$ of Writing)

$\begin{array}{lllll}\text { about } & \text { be } & \text { go } & \text { into } & \text { our } \\ \text { after } & \text { because } & \text { going } & \text { just } & \text { out } \\ \text { all } & \text { came } & \text { have } & \text { like } & \text { said } \\ \text { are } & \text { day } & \text { her } & \text { mum } & \text { some } \\ \text { as } & \text { down } & \text { his } & \text { not } & \text { were } \\ \text { back } & \text { get } & \text { home } & \text { one } & \text { with }\end{array}$

Essential List 4 ( 50 Words; $10 \%$ of Writing)

$\begin{array}{lllll}\text { again } & \text { do } & \text { next } & \text { people } & \text { time } \\ \text { an } & \text { first } & \text { night } & \text { put } & \text { took } \\ \text { around } & \text { food } & \text { no } & \text { ran } & \text { two } \\ \text { big } & \text { from } & \text { now } & \text { saw } & \text { us } \\ \text { by } & \text { good } & \text { off } & \text { school } & \text { very } \\ \text { can } & \text { has } & \text { old } & \text { see } & \text { well } \\ \text { come } & \text { him } & \text { only } & \text { started } & \text { what } \\ \text { could } & \text { house } & \text { or } & \text { their } & \text { will } \\ \text { dad } & \text { if } & \text { other } & \text { them } & \text { would } \\ \text { did } & \text { little } & \text { over } & \text { this } & \text { your }\end{array}$


Essential List 5 ( 50 Words; $5 \%$ of Writing)

$\begin{array}{lllll}\begin{array}{l}\text { am } \\ \text { another }\end{array} & \begin{array}{l}\text { door } \\ \text { everyone }\end{array} & \begin{array}{l}\text { last } \\ \text { left }\end{array} & \begin{array}{l}\text { once } \\ \text { play }\end{array} & \begin{array}{l}\text { through } \\ \text { told }\end{array} \\ \text { away } & \text { family } & \text { long } & \text { really } & \text { too } \\ \text { bed } & \text { five } & \text { looked } & \text { room } & \text { walked } \\ \text { been } & \text { found } & \text { made } & \text { something } & \text { want } \\ \text { before } & \text { friend } & \text { man } & \text { still } & \text { way } \\ \text { best } & \text { fun } & \text { more } & \text { thing } & \text { where } \\ \text { brother } & \text { heard } & \text { morning } & \text { think } & \text { which } \\ \text { called } & \text { here } & \text { name } & \text { thought } & \text { who } \\ \text { car } & \text { know } & \text { never } & \text { three } & \text { year }\end{array}$

Essential List 6 (70 Words; $5 \%$ of Writing)

\begin{tabular}{|c|c|c|c|c|}
\hline also & cool & eyes & head & jump \\
\hline always & dark & fell & hit & knew \\
\hline asked & decided & felt & how & later \\
\hline black & dog & find & inside & life \\
\hline boy & eat & four & its & live \\
\hline bus & end & gave & it's & lot \\
\hline cat & even & getting & I'II & lunch \\
\hline coming & every & great & I'm & make \\
\hline minutes & place & sister & top & water \\
\hline most & ready & sleep & town & while \\
\hline much & ride & suddenly & tree & why \\
\hline nice & right & take & turned & window \\
\hline opened & run & tell & until & woke \\
\hline outside & say & ten & wanted & yes \\
\hline
\end{tabular}

Essential List 7 (60 Words; $3 \%$ of Writing)

$\begin{array}{lllll}\text { any } & \text { each } & \text { ground } & \text { money } & \text { soon } \\ \text { baby } & \text { ever } & \text { guard } & \text { mother } & \text { stay } \\ \text { bad } & \text { everything } & \text { hand } & \text { myself } & \text { stop } \\ \text { ball } & \text { face } & \text { happened } & \text { new } & \text { swimming } \\ \text { being } & \text { fast } & \text { happy } & \text { parents } & \text { tea } \\ \text { bit } & \text { father } & \text { help } & \text { picked } & \text { than } \\ \text { boat } & \text { few } & \text { hole } & \text { playing } & \text { tried } \\ \text { bought } & \text { finally } & \text { hot } & \text { presents } & \text { under } \\ \text { camp } & \text { finished } & \text { hour } & \text { road } & \text { wait } \\ \text { dead } & \text { game } & \text { let } & \text { side } & \text { won } \\ \text { died } & \text { girl } & \text { look } & \text { small } & \text { work } \\ \text { doing } & \text { gone } & \text { many } & \text { sometimes } & \text { world }\end{array}$

